\title{
Organic carbon recovery modeling for a rotating belt filter and its impact assessment
} on a plant-wide scale

\author{
Behera, Chitta Ranjan; Santoro, Domenico; Gernaey, Krist V.; Sin, Gürkan
}

Published in:

Chemical Engineering Journal

Link to article, DOI:

10.1016/j.cej.2017.11.091

Publication date:

2018

Document Version

Peer reviewed version

Link back to DTU Orbit

Citation (APA):

Behera, C. R., Santoro, D., Gernaey, K. V., \& Sin, G. (2018). Organic carbon recovery modeling for a rotating belt filter and its impact assessment on a plant-wide scale. Chemical Engineering Journal, 1965-1976.

https://doi.org/10.1016/j.cej.2017.11.091

\section{General rights}

Copyright and moral rights for the publications made accessible in the public portal are retained by the authors and/or other copyright owners and it is a condition of accessing publications that users recognise and abide by the legal requirements associated with these rights.

- Users may download and print one copy of any publication from the public portal for the purpose of private study or research.

- You may not further distribute the material or use it for any profit-making activity or commercial gain

- You may freely distribute the URL identifying the publication in the public portal 


\section{Accepted Manuscript}

Organic carbon recovery modeling for a rotating belt filter and its impact assessment on a plant-wide scale

Chitta Ranjan Behera, Domenico Santoro, Krist V. Gernaey, Gürkan Sin

PII:

$$
\text { S1385-8947(17)32013-2 }
$$

DOI:

$$
\text { https://doi.org/10.1016/j.cej.2017.11.091 }
$$

Reference:

$$
\text { CEJ } 18062
$$

To appear in:

$$
\text { Chemical Engineering Journal }
$$

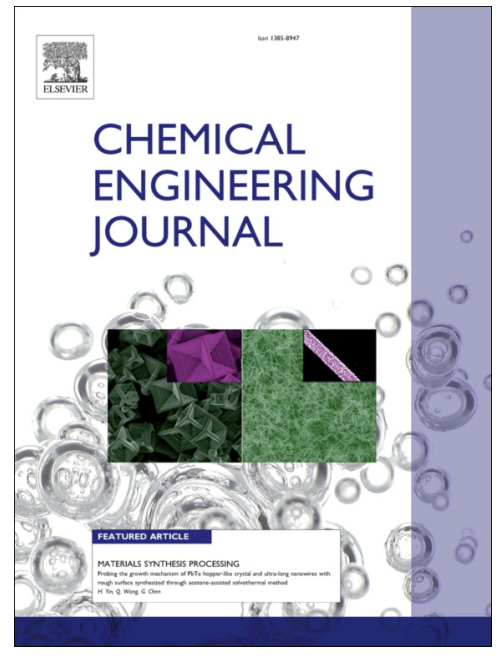

Please cite this article as: C.R. Behera, D. Santoro, K.V. Gernaey, G. Sin, Organic carbon recovery modeling for a rotating belt filter and its impact assessment on a plant-wide scale, Chemical Engineering Journal (2017), doi: https://doi.org/10.1016/j.cej.2017.11.091

This is a PDF file of an unedited manuscript that has been accepted for publication. As a service to our customers we are providing this early version of the manuscript. The manuscript will undergo copyediting, typesetting, and review of the resulting proof before it is published in its final form. Please note that during the production process errors may be discovered which could affect the content, and all legal disclaimers that apply to the journal pertain. 


\title{
Organic carbon recovery modeling for a rotating belt filter and its impact assessment on a plant-wide scale
}

\author{
Chitta Ranjan Behera ${ }^{\mathrm{a}}$, Domenico Santoro ${ }^{\mathrm{b}}$, Krist V. Gernaey ${ }^{\mathrm{a}}$, Gürkan Sin ${ }^{\mathrm{a}}$ \\ ${ }^{a}$ Process and Systems Engineering Center (PROSYS), Department of Chemical and Biochemical \\ Engineering, Technical University of Denmark, Building 229, 2800 Kgs. Lyngby, Denmark \\ ${ }^{b}$ Trojan Technologies, 3020 Gore Road, London, Ontario Canada, N5V 4 Tr7
}

\section{Abstract}

In this study, we perform a systematic plant-wide assessment of the organic carbon recovery concept on wastewater treatment plants by an advanced cellulose recovery enabling technology called rotating belt filter (RBF). To this end, first, an empirical model is developed to describe organic carbon recovery by the RBF, which is then used for the plant-wide performance evaluation to further understand the impact of organic carbon recovery by framing four different scenarios. The key features of the scenario analysis are: (i) an RBF operating with thick mat increases methane production (around $10 \%$ ) and brings down aeration energy demand (by $8 \%$ ) compared to the primary clarifier (PC) and, (ii) the sludge retention time (SRT) of the activated sludge (AS) tank increases by $55 \%$ when an RBF runs with thick mat and therefore promotes higher nitrification rate, (iii) organic carbon recovery by the RBF does not increase the greenhouse gas $\left(\mathrm{N}_{2} \mathrm{O}\right)$ emission. Further sensitivity analysis indicates that the impact of the organic carbon recovery concept depends on the wastewater characteristics, especially the cellulose content and its biodegradability. Overall, the organic carbon recovery technology can be used to provide plant specific improvements achieved by maximizing organic carbon recovery in the form of methane gas or enhancing nitrogen removal depending on the treatment plant operation objectives and priorities. Keywords: Organic carbon recovery, RBF, Cellulose, Impact assessment, Methane production, Aeration energy demand 


\section{Introduction}

In recent years, resource recovery from wastewater treatment plants (WWTP) is gaining more attention and the organic carbon recovery in the form of toilet paper fibers is in focus in the present study. The wastewater (mainly in western countries) contains cellulose fibers that represent $30-50 \%$ of the total suspended solids $[1,2]$. These cellulose fibers originates from toilet paper. The use of the toilet paper per person is expected to reach a range of 10 - $14 \mathrm{~kg}$ per year [1] and it can further grow based on population growth and sanitary awareness. The dominant component in the toilet paper is fibrous cellulose which has a slower microbial hydrolysis rate. The cellulose can directly enter into the activated sludge (AS) process if it is not efficiently separated in the primary treatment.

Under aerobic conditions, only $60 \%$ of the cellulose is degradable with a sludge retention time (SRT) of $4-5$ weeks [3] which is quite high compared to the normal SRT operating range of a complete-mix AS process (5 - 15 days) [4]. However, under anaerobic conditions the biodegradability of cellulose is quite encouraging (nearly $60 \%$ biodegradable under mesophilic conditions and the SRT of 2 weeks[2]) compared to the AS process and depends on operating temperature regime and selection of reactor $[2,5]$. Therefore, the energy consumption in the WWTP can be reduced if somehow cellulose fibers can be diverted smartly from the primary treatment stage and fed to an anaerobic digester for production of methane gas [2].

A Recent study [1] confirms that the cellulose fibers can be efficiently recovered by using a rotating belt filter (also known as Salsnes filter) with a fine mesh size of $0.35 \mathrm{~mm}$. It is (as shown in Figure 1) predominantly used as a mechanical treatment with special focus on achieving a higher suspend solids removal, and it works based on cake filtration and sieving (more discussion on the working principle is presented in the materials and methods sec-

\footnotetext{
* Corresponding author

Email address: gsi@kt.dtu.dk (Gürkan Sin)
} 
tion). The sludge collected from the RBF is enriched in cellulose fibers (approximately 80 $90 \%$ of the recovered organic mass $[1,2])$ and has significantly higher volatile solids content with excessive methane production potential compared to sludge collected from a traditional primary clarifier (PC) (cellulose fiber fraction is only 30 - 40\% of recovered organic mass) $[1,6]$. In a traditional WWTP, the PC is one of the unit operations (for primary treatment) which works based on gravity separation to remove total suspended solids (TSS) and lower the biological oxygen demand. The performance of the PC is many times constrained by a higher sludge blanket depth and hydraulic limitations (namely short hydraulic retention time (HRT), higher surface loading rate (SLR) and short-cireuiting). On the contrary, the performance of the RBF is not deteriorating due to short-circuiting and biological activity within the sludge blanket [7], but it can be solids limited (i.e., the mesh used for filtration can be clogged leading to inefficient separation). The selection of RBF technology over a PC depends on several factors such as footprint, plant capacity, greenhouse gas $\left(\mathrm{CO}_{2}\right)$ emission, primary effluent quality, influent suspended solids concentration, selective particle size fractionation [8]. For sewage waste water treatment application, the RBF with mesh size $0.35 \mathrm{~mm}$ is widely used and can achieve higher TSS removal efficiency compared to the PC $[1,7,9]$. Moreover, the higher carbon diversion from the mainline WWTP can further boost the energy production in the $\mathrm{AD}[10,11]$. Thus keeping energy neutrality and resources recovery awareness in mind, it is imperative to call for a more thorough study on efficient organic carbon recovery from the WWTP and its impact assessment on a plant-wide scale.

Literature review suggests that only a few studies are available related to developing a mathematical model for the rotating belt filter $[12,13]$ and no comprehensive study has been published on its impact assessment (in terms of aeration energy requirement, methane gas production, nitrous oxide $\left(\mathrm{N}_{2} \mathrm{O}\right)$ gas emission etc.) on a plant-wide level in comparison to a PC. The mechanistic model presented recently by De Groot et al.[13] is mainly useful for design exploration and sizing of the RBF. However, its application for plant-wide analysis 
may not be suitable due to the computational limitations (considering plant-wide simulation). Moreover calibration of the mechanistic model parameters may also need significantly more effort (as it requires measurement of specific cake mass, influent TSS, local removal efficiency, total flow resistance, etc.). Therefore a simplified model such as an empirically based model with a lower number of model parameters will be more pragmatic to initiate plant-wide assessment studies of RBF performance.

The objective of the present study is to evaluate the plant-wide impact of the organic carbon recovery concept on key performance indicators, such as effluent quality, methane gas production (from the anaerobic digester $(\mathrm{AD})$ ), aeration energy demand (for AS), $\mathrm{N}_{2} \mathrm{O}$ gas emission (from AS), SRT (for AS tank). Thus, to carry out an in-depth plant-wide impact assessment study two different primary treatment technologies are considered namely PC and the RBF. To accomplish the goal; first, an empirical model is developed for the RBF and subsequently validated. Then, four scenarios are framed to mimic the real world engineering questions (as depicted in Table 1) and analyzed one by one. A modified benchmark simulation model no 2 (BSM2) framework is developed where the PC model is replaced with the proposed RBF model. The primary focus of the present work is to highlight the additional value (such as enhancement in the methane gas production, reduction in aeration energy (AE) demand, and $N_{2} O$ gas emission etc.) associated with the organic carbon recovery concept, by performing a series of simulation analysis, namely plant-wide steady state and dynamic simulation followed by sensitivity analysis on the cellulose load in the influent wastewater.

\section{Materials and methods}

\subsection{Rotating belt filter - working principle and empirical model development}

The RBF (Figure 1) works based on cake filtration which removes suspended solids from wastewater by using a polyester screen with a certain mesh size. It is operated by 
continuously moving the belt on which the wastewater passes, and during the process, solids are retained on the filter mat and form a layer which is then further separated by the air knife. The mat is periodically cleaned by compressed air and a water spray to avoid clogging of the screen $[7,8]$. The mesh size for the RBF screen varies from 50 to 500 micron which increases the application domain. For this study, the SF 2000 model (with filter screen mesh size $0.35 \mathrm{~mm}$ ) is considered for empirical model development as it is widely used to remove suspended solids from sewage water. The suspended solid removal depends on multiple operating conditions (such as sieving rate, water flow rate, fine mesh size, etc.) and inlet wastewater constituents (mainly TSS). However, from an application point of view, the mesh size is fixed for a particular type of wastewater (for example, the SF - 2000 with 0.35 $\mathrm{mm}$ is mostly preferred for municipal wastewater which is also considered for the present study). The flow rate to the RBF also does not vary frequently (due to the equalization tank before primary treatment) from a plant operation point of view. Thus the influence of these operating parameters on TSS removal efficiency may not be that significant. On the contrary, the sieving rate and TSS in the influent wastewater have a strong correlation with the TSS removal efficiency $[7,9,14]$.

In the present work influent TSS and corresponding removal efficiency are used to develop the empirical model as data corresponding to these variables are explicitly available. It is also believed that TSS measurement is frequently used and handy for a plant operator compared to sieving rate, and this will further increase the model usability. The proposed empirical model (Equation 1) is developed by using the experimental data reported in the paper by Franchi and Santoro [7] as training dataset, and the datasets reported elsewhere $[7,15]$ are used for the model validation. The TSS removal efficiency model equation for an $\mathrm{RBF}$ is presented in equation 1.

$$
\eta_{T S S}=100 \cdot\left(1-K_{1} \cdot e^{-K_{2} \cdot T S S_{i n}}\right)
$$


Where, $K_{1}$ and $K_{2}$ are model parameters estimated by fitting the model to the field data using a robust regression technique (as mentioned in Equation 2 to 5). The TS $S_{\text {in }}$ is the concentration $(\mathrm{g} / \mathrm{L})$ of influent suspended solids to an RBF. The $\eta_{T S S}$ (TSS removal efficiency)is always predicted in percentage (\%) units and only requires the $T S S_{i n}$.

$$
\begin{array}{r}
K=\arg \min \sum w_{i}\left(y_{i}^{\text {exp }}-y_{i}^{\text {pred }}\right)^{2} \\
w_{i}=\frac{1}{1+r^{2}} \\
r=\frac{\left(y_{i}^{\text {exp }}-y_{i}^{\text {pred }}\right)}{\operatorname{tune} . S \cdot \sqrt{1-h}} \\
S=\frac{\text { median }\left(\operatorname{abs}\left(\left(y_{i}^{\text {exp }}-y_{i}^{\text {pred }}\right)-\text { median }\left(y_{i}^{\text {exp }}-y_{i}^{\text {pred }}\right)\right)\right.}{0.6745}
\end{array}
$$

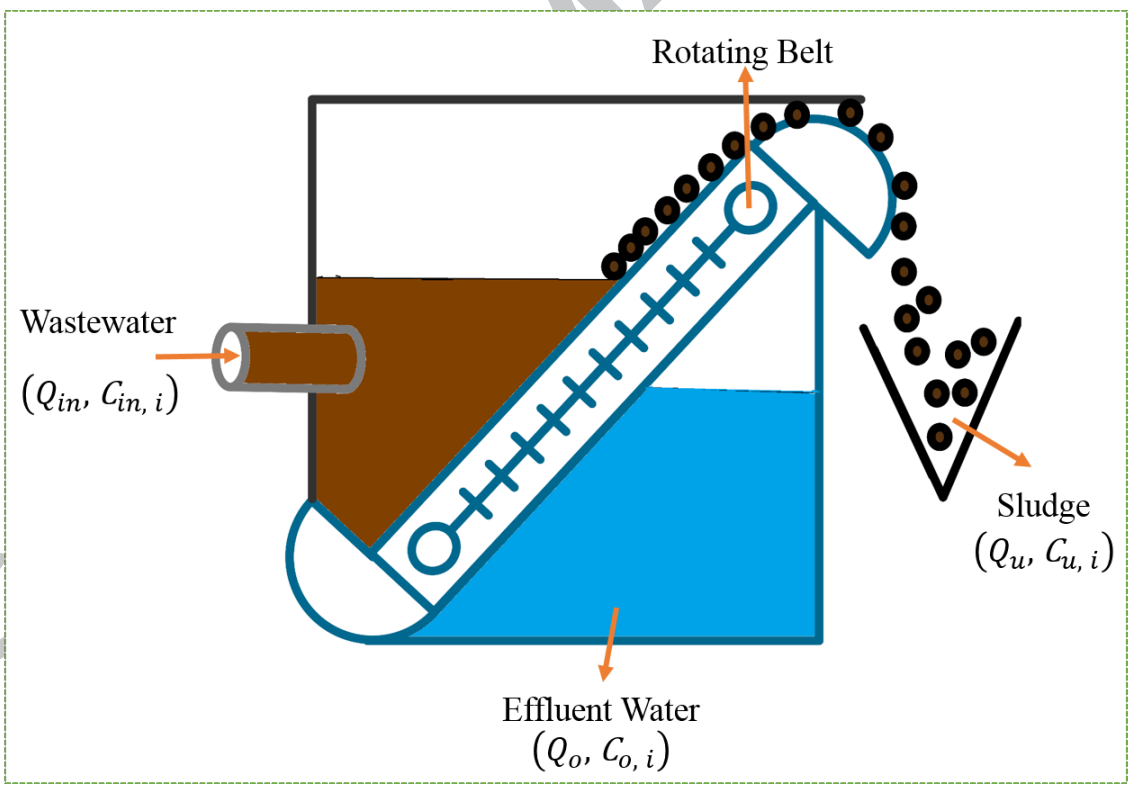

Figure 1: Schematic diagram of the rotating belt filter (model SF - 2000) showing it's working principle and also used for developing mass balance model.

It is suggested to run the RBF with a thick filter mat when the primary objective is to achieve higher TSS removal efficiency [9] . If a thick filter mat is allowed on the filter screen, then it acts as a double layer, and the original mesh size (which is $0.35 \mathrm{~mm}$ ) was reduced further, which ultimately helps to remove more inert particulates and slowly biodegradable 
particulate material along with cellulose. The corresponding operating procedure can be obtained by running the rotating belt at low speed which facilitates organic particulates to form a thick mat on the screen. It can further lead to a favorable condition for higher methane production in the $\mathrm{AD}$ as well as lower aeration energy consumption in the AS. On the other hand, if no mat formation is maintained by running the rotating belt at higher speed then there will be a significant improvement in denitrification rate $[16,17]$ compared to the situation with a thick mat. However, the TSS removal efficiency reduces as a consequence, which translates to lower methane production and higher aeration energy demand compared to the situation with a thick mat. For more detailed information on the working principle and application of an RBF, the readers are suggested to consult other papers $[7,9,12]$. To further understand the impact of these operating conditions at the plant-wide scale, scenarios for further analysis are framed (description is presented in Table 1) and implications of each scenario are discussed separately and put in the context of engineering practice.

\subsection{Scenarios for framing impact assessment of organic carbon recovery}

In a plant, the $\mathrm{PC}$ is used to remove the suspended solids. However due to increased awareness on the potential of organic carbon recovery (mainly cellulose), a plant engineer would like to understand the impact of low cellulose removal (from primary treatment) on overall plant performance (namely methane gas production, aeration energy demand, $\mathrm{N}_{2} \mathrm{O}$ gas emission, effluent quality etc.) and further to explore the potential alternatives for retrofitting the PC. Thus, four scenarios are framed (as depicted in Table 1) to address the plant engineer's questions. 
Table 1: Description of the scenarios used for organic carbon recovery impact assessment in plantwide scale. Four scenarios are formulated to explain plant engineer's questions.

\begin{tabular}{|l|l|}
\hline \multicolumn{1}{|c|}{ Framing the scenarios analysis for organic carbon recovery } \\
\hline Scenario - 1 & $\begin{array}{l}\text { A plant engineer believes that the PC may not be the most efficient technology } \\
\text { to achieve higher cellulose recovery as also reported in literature }[1] \text {. Therefore, } \\
\text { the objective here is to study the impact of lower cellulose recovery by the PC } \\
\text { on overall plant performance. }\end{array}$ \\
\hline Scenario - 2 & $\begin{array}{l}\text { A plant engineer wants to retrofit the PC with a best available alternative. } \\
\text { Hence, the aim of this scenario is to understand the impact of RBF performance } \\
\text { on the plant-wide scale, and it is also decided to operate the RBF without } \\
\text { allowing thick mat formation (additional layer) on the rotating belt. }\end{array}$ \\
\hline Scenario - 3 & $\begin{array}{l}\text { A plant engineer wishes to run the RBF with different operating conditions } \\
\text { compared to scenario } 2 . \text { Therefore, he/she intends to operate the RBF with } \\
\text { thick mat formation on the rotating belt in order to maximize carbon capture } \\
\text { in the primary treatment step. Hence, the goal is to examine the effect of } \\
\text { changing the operating conditions of the RBF on overall plant performance. }\end{array}$ \\
\hline Scenario - 4 & $\begin{array}{l}\text { A plant engineer wants to explore that by retrofitting the RBF with a PC, } \\
\text { can he/she minimize the consumption of external carbon usage which is } \\
\text { generally used for denitrification. Thus, he/she decides to quantify the in- } \\
\text { fluence of running the RBF without thick mat formation combined with } \\
\text { discontinuing the addition of external carbon to the anoxic tank. }\end{array}$ \\
\hline
\end{tabular}

\subsection{Plant-wide evaluation framework for organic carbon recovery impact assessment}

The chemical engineering community has demonstrated the importance of plant-wide modeling and simulation for a long time, and the wastewater research community is also realizing the advantages of the plant-wide analysis approach. To foster the plant-wide analysis, the IWA task group on benchmarking of control strategies for wastewater treatment plants has consistently developed new models and tools which describe the most conventional unit processes within a wastewater treatment system ( such as primary treatment, activated sludge, anaerobic digestion, etc.). Pertinent to plant-wide evaluation, the Benchmark Simulation Model No. 2 (BSM2) [18, 19] was developed by the IWA task group as a convenient and commonly used framework for plant-wide analysis. The conventional BSM2 frame work has also further expanded to several versions to incorporate different $\mathrm{N}_{2} \mathrm{O}$ gas emission 
models[20, 21] (such as one pathway and two pathway) and phosphorous removal[22].

\subsubsection{Modified BSM2 plant layout and simulation strategy}

In this work, the BSM2 plant presented by Jeppsson et al. [19] is modified (as depicted in Figure 2) by retrofitting the PC with an RBF with the aim to use it to study the impact of organic carbon recovery by an RBF compared to the PC. The proposed plant layout consists of two sections, namely the wastewater line consists of an RBF, an AS unit and a secondary settler, whereas the sludge line consists of a sludge thickener, an AD, a de-watering unit and a storage tank. A new model is proposed for an RBF (discussed in the rotating belt filter section) and implemented to calculate the organic carbon (cellulose and other particulates) recovered from the mainstream. The AS unit, modeled using the activated sludge model no 1 (ASM1) [23] consists of five compartments, in which the first two are anoxic, and the last three are aerobic. The secondary settling tank is modeled as a non-reactive secondary settler using the exponential settling velocity function proposed by Takács et al. [24]. Likewise, the $\mathrm{AD}$ is framed using the widely used anaerobic digestion model no 1 (ADM1) [25]. Further to extend the study of carbon recovery impact on $\mathrm{N}_{2} \mathrm{O}$ emission, two different models (as shown in Figure 8 ) are considered which are extension of Hiatt and Grady [26], Guo and Vanrolleghem [27] and Domingo-Félez and Smets [28]. For additional details on design and operating conditions, the reader is referred to the papers by Gernaey et al. [18] and Jeppsson et al. [19].

The simulation strategy fist follows a closed loop steady state analysis on the modified BSM2 framework (as depicted in Figure 2). Afterwards, a dynamic simulation is also carried out to confirm the trends observed (in effluent quality) from steady state analysis and further to compare the transient behavior of $\mathrm{N}_{2} \mathrm{O}$ gas emission in the four scenarios. For both simulations (steady state and dynamic) it is decided to maintain the dissolved oxygen (DO) concentration at $1 \mathrm{mg} / \mathrm{l}$ for all the three aerobic tanks (also used in other literature [20]) by manipulating the oxygen mass transfer coefficient $\left(k_{l} a\right)$, or in other words, ideal DO control 


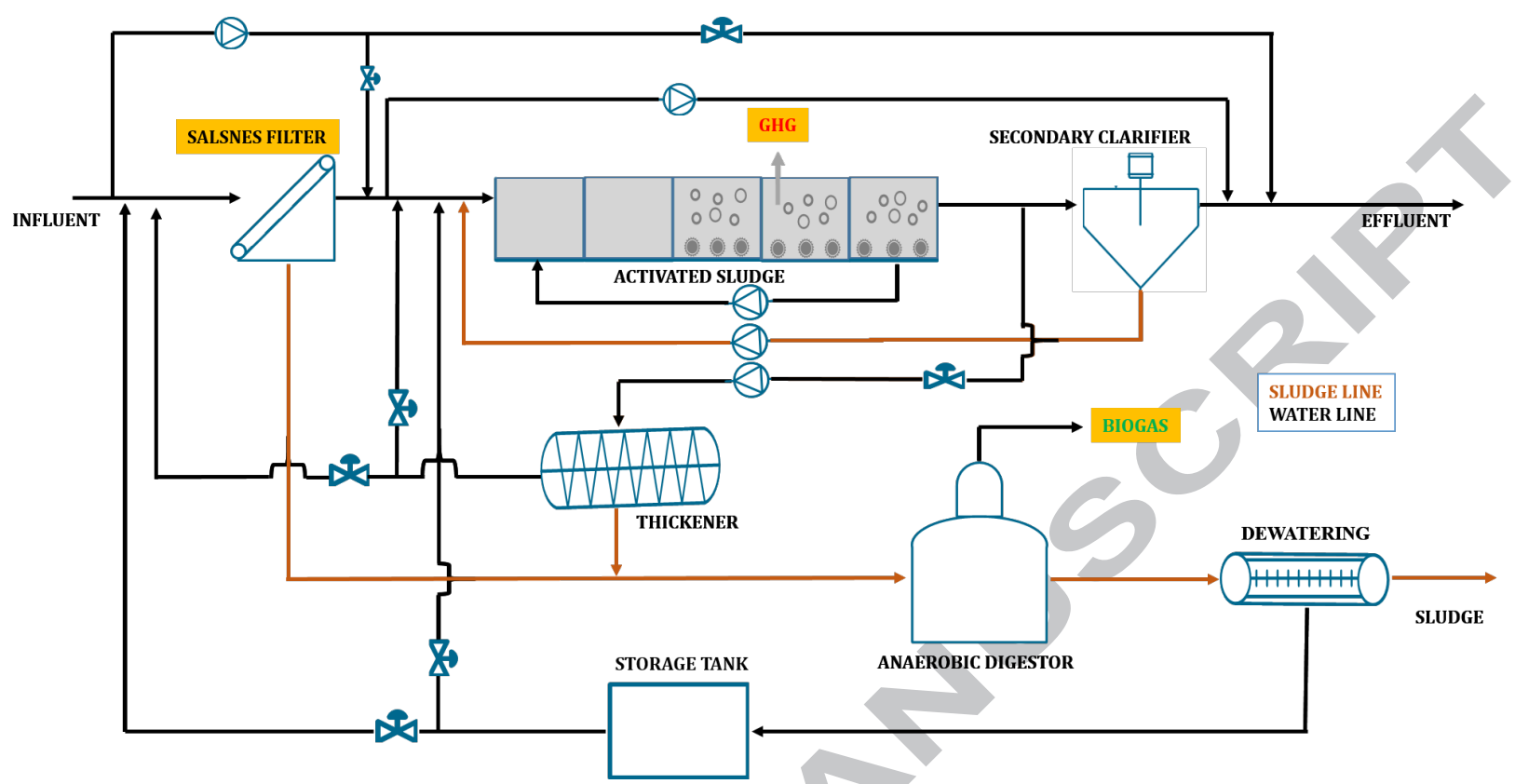

Figure 2: General overview of the modified BSM2 plant for plantwide organic carbon recovery impact assessment. The modified BSM2 framework used for simulating four scenarios: scenario 1 (using PC), scenario 2 (using RBF without thick mat), scenario 3 (using RBF with thick mat), scenario 4 (using RBF without thick mat and no addition of external carbon).

is assumed. Furthermore, it is also decided to maintain the TSS of the last aerobic tank at

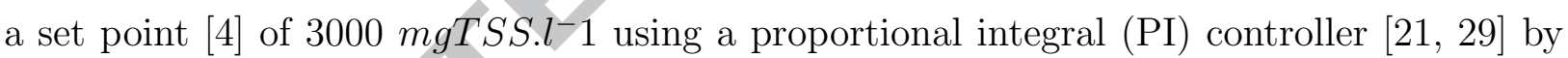
manipulating the wastage flow rate, which is connected to the thickener in the side stream. The objective behind the implementation of the TSS controller is to observe the impact of higher carbon recovery on the SRT of the AS tank. The external carbon addition is fixed to $400000 \mathrm{mg}$ COD/l with a flow rate of $2 \mathrm{~m}^{3} / \mathrm{d}$ for scenario 1 to 3 and for the scenario 4 , it is set to zero in order to explore it's impact on denitrification and further to explore the limitation of an RBF operating without thick mat formation. For the RBF (both with and without thick mat), the ratio of sludge flow rate to the influent flow rate is taken as 0.007 (i.e., $0.7 \%$ of influent flow) which is also the case for the PC in the BSM2 model [19]. In order to perform plant-wide simulation, the influent wastewater suggested by Gernaey et al. [30] is further modified (steps are discussed in calibration of wastewater COD section) to incorporate cellulose as a separate state and used for the simulation study. The influent 
load is designed for 100,000 people equivalent in which $80 \%$ of the load originates from households and $20 \%$ from industrial activities. For steady state analysis, the flow rate weighted average influent concentrations are used whereas the dynamic simulation is carried out for 609 days and the final 364 days are used for plant performance evaluation.

\subsubsection{Calibration of wastewater COD fraction for plant-wide analysis}

The influent wastewater data of the BSM2 proposed in Gernaey et al. [30] can not directly be used for our study as it does not include the cellulose contribution to the total chemical oxygen demand (COD) (where TCOD $=S_{S}+S_{I}+x_{S}+x_{C}+x_{I}+X_{B H}+X_{B A}$ $\left.+X_{P}\right)$. Thus to analyze the cellulose impact on plant performance, the COD fractions of the influent wastewater are calibrated (i.e., the inert and slowly biodegradable particulates) by implementing the proposed five steps (1 - 5) algorithm. During the calibration, it is assumed that the cellulose (which is $30 \%$ of influent COD [1]) is derived from slowly biodegradable particulates and inert particulates. The steps for calibration of inert and slowly biodegradable particulate COD are given as follows:

1. Calculate old inert particulate fraction as $\frac{X_{I}}{X_{I}+X_{S}}$ and old slowly biodegradable fraction as $\left(\frac{X_{S}}{X_{I}+X_{S}}\right)$.

2. Calculate the cellulose concentration as $x_{C}=0.3$.(TCOD).

3. Calculate the new total amount of inert and slowly biodegradable material as $\left(x_{I}+\right.$ $\left.x_{S}\right)=X_{I}+X_{S}-x_{C}$.

4. Calculate the calibrated inert particulate concentration as $x_{I}=\frac{X_{I}}{X_{I}+X_{S}} \cdot\left(x_{I}+x_{S}\right)$

5. Calculate the calibrated slowly biodegradable particulate concentration as $x_{S}=\frac{X_{S}}{X_{I}+X_{S}} \cdot\left(x_{I}+x_{S}\right)$.

The calibrated wastewater influent data (using the above algorithm) are further used for both steady state (presented in Table 2) and dynamic simulations (refer SI, Figure 1) using the proposed modified BSM2 framework. 
Table 2: Calibrated COD fractionation used for steady state simulation

\begin{tabular}{|l|l|l|l|l|}
\hline Symbols & Description & $\begin{array}{l}\text { Default } \\
\text { value }[30]\end{array}$ & $\begin{array}{l}\text { Calibrated } \\
\text { Value }\end{array}$ & Units \\
\hline$S_{I}$ & Soluble inert organic matter & 27.23 & 27.23 & gCOD.m $m^{-3}$ \\
\hline$S_{s}$ & Readily biodegradable substrate & 58.18 & 58.18 & $g C O D \cdot m^{-3}$ \\
\hline$x_{C}$ & Particulate cellulose matter & 0 & 177.75 & $g C O D \cdot m^{-3}$ \\
\hline$X_{I}$ & Particulate inert organic matter & 92.5 & 56.47 & $g C O D . m^{-3}$ \\
\hline$X_{S}$ & Slowly biodegradable substrate & 363.94 & 222.20 & $g C O D . m^{-3}$ \\
\hline$X_{B H}$ & Active heterotrophic biomass & 50.68 & 50.68 & $g C O D . m^{-3}$ \\
\hline$X_{B A}$ & Active autotrophic biomass & 0 & 0 & $g C O D . m^{-3}$ \\
\hline$X_{P}$ & Particulate products (biomass decay) & 0 & 0 & $g C O D . m^{-3}$ \\
\hline
\end{tabular}

\subsubsection{The rotating belt filter model}

The mathematical model equations for both underflow (enriched in sludge) and overflow (enriched in clear water) are developed based on the mass balance concept. The schematic overview of the RBF model is presented in the Figure 1.

The concentration of each influent fraction in the overflow is represented by the equations 6 to 7 .

$$
\begin{array}{r}
Q_{o}(t)=Q_{i n}(t)-Q_{u}(t) \\
C_{o, i}(t)=\left(1-\frac{\eta_{p, i}}{100}\right) \cdot C_{i n, i}(t) \cdot \frac{Q_{i n}}{Q_{o}}
\end{array}
$$

Likewise, the concentration of each fraction in the underflow is represented by the equations 8 to 9.

$$
\begin{array}{r}
Q_{u}(t)=f_{u} \cdot Q_{i n}(t) \\
C_{u, i}(t)=\left(\frac{\eta_{p, i}}{100} \cdot \frac{Q_{i n}(t)}{Q_{u}(t)}+\left(1-\frac{\eta_{p, i}}{100}\right)\right) \cdot C_{i n, i}(t)
\end{array}
$$

This developed RBF model is further used for scenarios analysis (i.e., for scenarios 2,3 and 
4) with different particulates removal efficiency as depicted in Table 3. The brief description of each parameter associated with the RBF model and its value is presented in SI (refer Table 1).

\subsubsection{The $\mathrm{N}_{2} \mathrm{O}$ model - using one pathway and two pathways}

In oder to understand the impact of carbon recovery (by RBF and PC) on $\mathrm{N}_{2} \mathrm{O}$ gas emission, the ASM1 model is extended (to incorporate the one pathway and two pathway model separately) based on the understanding from Hiatt and Grady [26], Guo and Vanrolleghem [27] and Domingo-Félez and Smets [28]. In this section, it is important to note that these $\mathrm{N}_{2} \mathrm{O}$ models are only used to generate $\mathrm{N}_{2} \mathrm{O}$ emission data for the discussion section in the results (see the Table 7). So far there is no consensus among research communities to select one model to describe the nitrification phenomena by AOB (ammonium oxidizing bacteria). Therefore two alternative models (as shown in Figure 8) are used to verify the impact of organic carbon recovery on nitrous oxide $\left(\mathrm{N}_{2} \mathrm{O}\right)$ emission which is an important greenhouse gas with global warming potential equivalent to 300 times the global warming potential of carbon dioxide. In a WWTP, the $\mathrm{N}_{2} \mathrm{O}$ can be produced both in the denitrification process (heterotrophic bacteria (HB) are the key players) and the nitrification process (where AOB are the main contributors) $[20,28,32,33]$. The pathways/models [26] for the $\mathrm{N}_{2} \mathrm{O}$ production from the denitrification process are straightforward (i.e $\mathrm{NO}_{3}^{-}->\mathrm{NO}_{2}^{-}->\mathrm{NO}->\mathrm{N}_{2} \mathrm{O}$ $\rightarrow N_{2}$ ), whereas for the nitrification process, several pathways (mainly classified as one pathway and two pathways model) have been proposed $[27,28]$ with the aim to quantify the $\mathrm{N}_{2} \mathrm{O}$ gas emission. The $\mathrm{N}_{2} \mathrm{O}$ production (emission factors vary from $0.1-2.8 \%$ [32]) in a WWTP is also site specific and largely influenced by several operating parameters $[21,32,34]$ of the activated sludge process (such as dissolve oxygen concentration, Temperature, HRT etc.). To completely explain the nitrification and denitrification processes, nitrite-oxidizing 
Table 3: Description of particulates removal efficiency for each scenarios: scenario 1 (using PC), scenario 2 (using RBF without thick mat), scenario 3 (using RBF with thick mat), scenario 4 (using RBF without thick mat and no addition external carbon).

\begin{tabular}{|c|c|}
\hline Scenarios & Particulate removal efficiency matrix \\
\hline Scenario - 1 (with PC) & $\begin{array}{l}\eta_{C O D}(t)=f_{\text {corr }} .\left(2.88 f_{X}-0.118\right) .\left(1.45+6.15 . \ln \left(t_{h}(t) .24 .60\right)\right)[19,31] \\
\eta_{p, i}=\frac{\eta_{C O D}}{f_{X}}[19] \\
\text { Each particulate fraction (such as } x_{I}, x_{S}, x_{C}, X_{B H} \text { etc.) is assumed to } \\
\left.\text { have equal removal efficiency (i.e } \eta_{p, i}\right) . \text { The detailed mathematical model } \\
\text { for the PC is presented in SI (Table } 1) .\end{array}$ \\
\hline $\begin{array}{l}\text { ( RBF without } \\
\text { thick mat ) }\end{array}$ & $\begin{array}{l}\eta_{T S S}=40 \%[1] \\
C O D_{\text {particulates }}=\frac{1}{0.75} \cdot\left(\eta_{T S S} \cdot T S S_{\text {in }}\right) \\
C O D_{\text {particulates }}=x_{C}+x_{I} \\
\eta_{x_{C}}=90 \% \text { (calculated from Ruiken et al.[1]) } \\
\eta_{x_{I}}=\frac{C O D_{\text {particulates }}-\eta_{C_{\text {In }}} \cdot x_{C_{i n}}}{x_{I_{i n}}} \\
\text { In these scenarios, the underlying assumption is that the RBF removes } \\
\text { mainly cellulose and inert particulates when the thick mat is not allowed } \\
\text { to be formed on the rotating belt screen. The removal efficiency for } x_{C} \\
\text { is calculated from the data reported by Ruiken et al. [1] and further the } \\
\text { removal efficiency for } x_{I} \text { is calculated using the above equation. The } \\
\text { total suspended solids (TSS) removal efficiency for these two scenarios } \\
\text { is adopted from the paper by Ruiken et al. [1] and subsequently the } \\
\text { efficiency for individual particulate fractions is calculated. }\end{array}$ \\
\hline (RBF with thick mat) & $\begin{array}{l}\eta_{T S S}=100 .\left(1-K_{1} \cdot e^{-K_{2} \cdot T S S_{i n}}\right) \text { (developed model, see equation 1) } \\
C O D_{\text {particulates }}=\frac{1}{0.75} \cdot\left(\eta_{T S S} \cdot T S S_{i n}\right) \\
C O D_{\text {particulates }}=x_{S}+X_{B H}+x_{C}+x_{I} \\
\eta_{x_{C}}=90 \% \text { (calculated from Ruiken et al.[1]) } \\
\eta_{x_{S}}=40 \% \text { (calculated from Ruiken et al.[1]) } \\
\eta_{x_{B H}}=50 \% \text { (calculated from Ruiken et al.[1]) } \\
\eta_{x_{I}}=\frac{C O D_{\text {particulates }}-\eta_{x_{X_{i n}}} \cdot x_{C_{i n}}-\eta_{x_{S_{i n}}} \cdot x_{S_{i n}}-\eta_{X_{B H}} \cdot X_{B H_{i n}}}{x_{I_{i n}}} \\
\text { For this scenario, the underlying assumption is that when an RBF oper- } \\
\text { ates with a thick mat, then it removes some fraction of biomass, slowly } \\
\text { biodegradable and inert particulates along with cellulose due to the dou- } \\
\text { ble layer formation (one is the screen another one is the suspended solids } \\
\text { thick layer). The TSS removal efficiency is estimated from the developed } \\
\text { model (see Equation } 1 \text { ). The removal efficiency for } x_{C}, X_{B H} \text { and } x_{S} \text { is } \\
\text { determined from the data reported by Ruiken et al. [1] and further the } \\
\text { removal efficiency }\left(\eta_{x_{I}}\right) \text { for } x_{I} \text { is calculated. }\end{array}$ \\
\hline
\end{tabular}


bacteria (NOB) model and denitrifcation models are adopted from the literature [26, 27, 28] as implemented and evaluated by Boiocchi et al. [35]. The details of the rate expressions for each pathway and the model parameters used for our study (plant-wide simulation) are provided in the SI (Table 3, 4, 5, 6) and the Boiocchi et al. [35].

\subsubsection{Evaluation criteria}

The impact of organic carbon recovery on four scenarios is evaluated based on several performance indicators, such as effluent quality index (EQI), methane gas production from $\mathrm{AD}$, aeration energy (AE) demand by AS tank, total $\mathrm{N}_{2} \mathrm{O}$ gas emission by AOB and $\mathrm{HB}$ (including both nitrification and denitrification), SRT of AS tank. The EQI correlation equation is adopted from Gernaey et al. [18], which is a weighted sum of the average loads of effluent TSS, COD, biological oxygen demand (BOD), total Kjeldahl Nitrogen (TKN) and nitrate $\left(\mathrm{NO}_{3}\right)$. The EQI is calculated for a period and is applied in dynamic simulation analysis (i.e., for the last 364 days as suggested by the IWA Task Group on Benchmarking of Control Strategies for Wastewater Treatment Plants for plantwide simulations.). It is measured as kilograms of pollutant units per day, and a higher effluent pollution load, corresponding to a more severe effluent quality violation. Since the EQI does not account for $\mathrm{N}_{2} \mathrm{O}$ gas emission, two emission factors (such as $\mathrm{N}_{2} \mathrm{O}$ emission factor 1 and 2) are calculated based on the TKN concentration at the inlet and removed from plant respectively [20]. The effluent discharge limits $[18,34]$ for major fractions, such as COD $\left(100 \mathrm{gCOD} . \mathrm{m}^{-3}\right)$, TSS $\left(30 \mathrm{gSS} . \mathrm{m}^{-3}\right)$, total nitrogen $(\mathrm{TN})\left(18 \mathrm{gN} . \mathrm{m}^{-3}\right)$ are used for both steady state and dynamic simulation analysis. Furthermore, to assess the impact of organic carbon recovery on plant energy saving, the AE demand for the AS process is calculated as it consumes around $55 \%$ of total plant energy demand [4] and the organic carbon diversion from the main line WWTP can make a tangible impact on the AS tanks energy consumption. Thus, all other things equal (mainly energy used for pumps in recycle, recirculation lines, etc), the AE demand for all the scenarios is calculated using the correlation model (developed for Degrmont DP230 
porous disks) suggested by Gernaey et al. [18]. The details of the model equations used to calculate the above critical factors are presented in the SI (refer SI, Equation 5 and 6).

\section{Results and discussions}

\subsection{Empirical model evaluation for an $R B F$}

The purpose is to describe TSS removal performance in the RBF, which can then be used in plant-wide assessment. Therefore a simple model is identified from the trends observed in experimental datasets reported in the literature [7, 15]. The proposed RBF model (as mentioned in Equation 1) relates the TSS removal efficiency to influent TSS concentration. It has only two parameters (such as $K_{1}-1.14$ and $K_{2}-2.87$ ) which are determined by using a robust regression technique (as mentioned in Equation 2 to 5). Here each residual is weighted by using the Cauchy weight $\left(w_{i}\right)[36]$ : putting a higher weight to small residuals and lower weight to large residuals. The $w_{i}$ is updated recursively in order to reduce the influence of outliers. The tuning parameters values such as tune -2.385 and $h-0$ are set by trial and error procedure in order to build higher accuracy model.

The adjusted regression coefficient $\left(R^{2} a d j\right)$ for the developed model is found to be 0.87 , which indicates that the model is not overfitted and able to capture the pattern despite the wide variation in the dataset (as shown in Figure 3). Further, the model is also tested with four independent data sets (as reported in Figure $4(\mathrm{a}-\mathrm{d})$ ). The model is clearly able to predict the removal efficiency with higher accuracy (within $95 \%$ confidence interval) especially for three of the datasets (as depicted in the Figure $4(\mathrm{a}-\mathrm{c})$ ). However in Figure 4 (d), the model prediction deviates for some data points (i.e., for TSS values ranging from $0.2-0.6 \mathrm{~g} / \mathrm{l}$ ) which is not the case for other datasets (Figure $4(\mathrm{a}-\mathrm{c})$ ). The calculated mean squared error (as depicted in Table 4) also shows that this indicator of the quality of the regression (Figure 4(d)) has quite a higher magnitude compared to the others. Operational variation (such as change in sieving rate) may have a contribution to the offset, which needs 


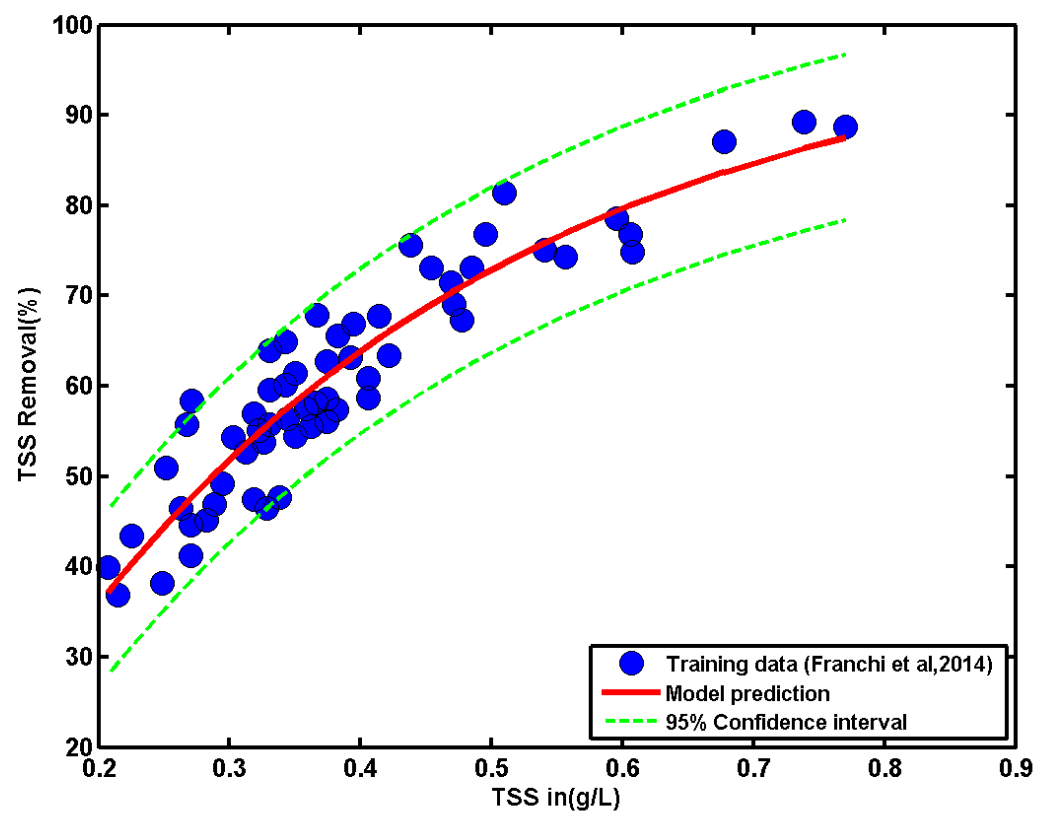

Figure 3: The total suspended solid (TSS) model (as presented in the Equation 1) fitted on the training dataset.

further investigation.

Table 4: The mean squared error (MSE) is calculated for training (Figure 3) and test datasets (Figure 4) to compare the performance of total suspended solid (TSS) model (as presented in the Equation 1).

\begin{tabular}{|c|c|c|c|c|c|}
\hline & Train dataset & Test dataset 1 & Test dataset 2 & Test dataset 3 & Test dataset 4 \\
\hline MSE & 20.53 & 39.51 & 51.15 & 18.53 & 193.56 \\
\hline
\end{tabular}

The model prediction is also extrapolated for three data points (in Figure $4(\mathrm{~d})$ ) though the model is built for the influent TSS range from $0.2-0.8 \mathrm{~g} / 1$ and its estimations are close to actual TSS removal efficiency. It is important to highlight here that the extrapolation of the empirical model outside the influent TSS range may be risky although the developed model is able to predict (as depicted in Figure $4(\mathrm{~d})$ ) the TSS removal efficiency. As the developed TSS model is built and validated on the higher TSS removal data (ranging from $40 \%$ to $90 \%$ ), therefore it is decided to use it for scenario - 3 where the RBF is operated 


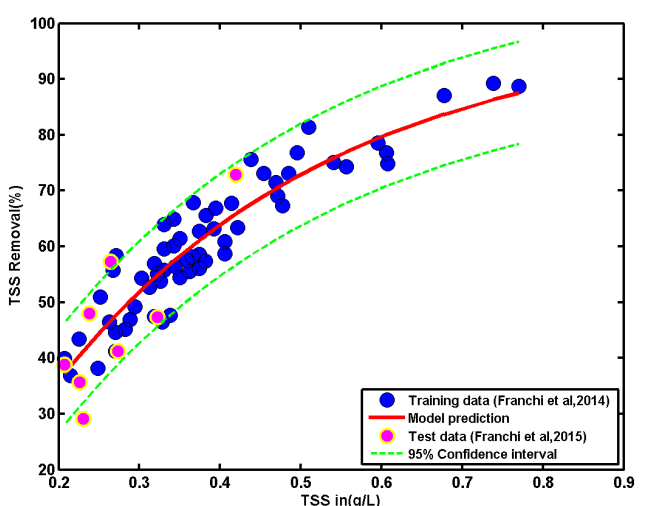

(a)

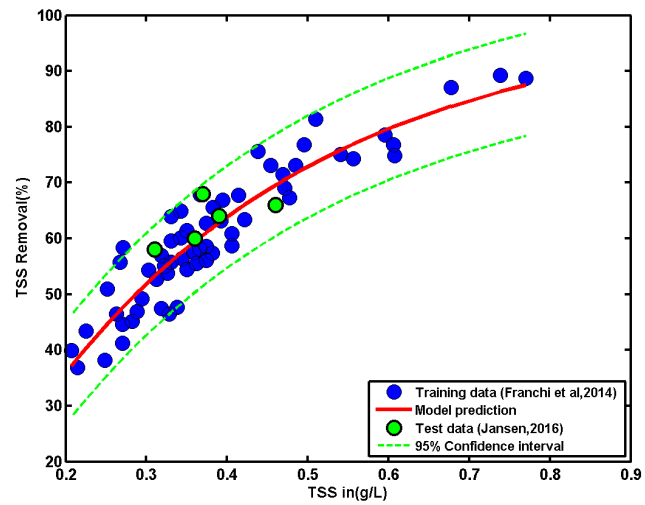

(c)

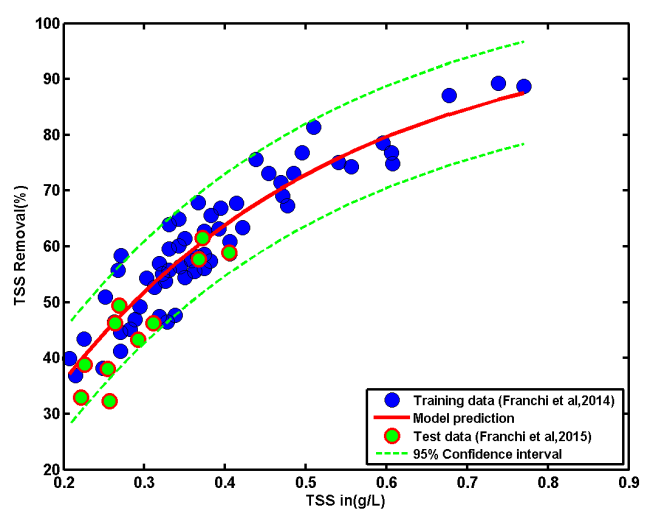

(b)

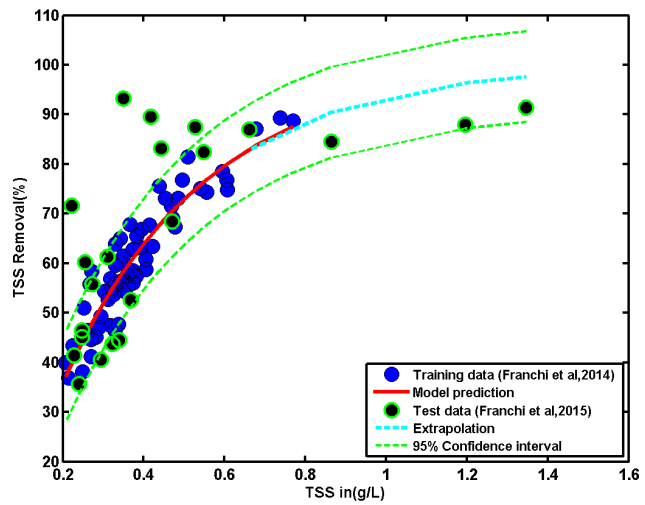

(d)

Figure 4: The total suspended solid (TSS) model (as presented in the Equation 1) is tested on the four independent datasets from Franchi and Santoro [7] (a,b,d) and Jansen [15] (c) 
with thick mat formation. In order to use the same TSS model for scenario - 2 (i.e., no thick mat formation) it is required to further calibrate with lower TSS removal efficiency data (which is out of scope for the present study).

\subsection{Implication of plant-wide steady state analysis for a WWTP}

The plant-wide steady state simulation is carried out for all four scenarios using the calibrated wastewater influent (see Table 2) where cellulose contributes by $30 \%$ of the total COD [1]. Here cellulose is introduced as a separate state variable which has a biodegradability around $25 \%$ in the AS [3] and $60 \%$ in the AD [2]. During the plant-wide analysis it was assumed that the extent of cellulose biodegradability is similar to the slowly biodegradable particulates and inert particulates $[1,2,3]$. The kinetic and stoichiometric parameter values reported in the ASM1 [23] are used for the present study. The developed RBF model along with individual particulate removal efficiency as explained earlier (see Table 3) are used for steady state analysis.

Table 5: Summary of key evaluation parameters results for all four scenarios, generated from the plant-wide steady state simulation: scenario 1 (using PC), scenario 2 (using RBF without thick mat), scenario 3 (using $\mathrm{RBF}$ with thick mat), scenario 4 (using RBF without thick mat and no addition of external carbon).

\begin{tabular}{|l|l|l|l|l|l|}
\hline $\begin{array}{l}\text { Assessment param- } \\
\text { eters }\end{array}$ & Units & Sc - 1 & Sc - 2 & Sc - 3 & Sc - 4 \\
\hline $\begin{array}{l}\text { Effluent COD concen- } \\
\text { tration }\end{array}$ & $g C O D . m^{-} 3$ & 46.19 & 45.94 & 46.13 & 45.89 \\
\hline $\begin{array}{l}\text { Effluent TN concen- } \\
\text { tration }\end{array}$ & $g N . m^{-} 3$ & 11.14 & 9.91 & 15.08 & 12.76 \\
\hline $\begin{array}{l}\text { Effluent ammonium } \\
\left(N H_{4}^{+}\right) \text {concentration }\end{array}$ & $g N . m^{-} 3$ & 0.19 & 0.26 & 0.15 & 0.20 \\
\hline $\begin{array}{l}\text { Effluent nitrate } \\
\left(N O_{3}^{-}\right) \text {concentration }\end{array}$ & $g N . m^{-} 3$ & 9.15 & 7.75 & 13.07 & 10.69 \\
\hline $\begin{array}{l}\text { Aeration energy con- } \\
\text { sumption }\end{array}$ & $K w h . d^{-} 1$ & 4009 & 4368 & 3842 & 4241 \\
\hline Methane production & $K g C H_{4} \cdot d^{-} 1$ & 1032 & 744 & 1086 & 692 \\
\hline $\begin{array}{l}\text { Sludge retention time } \\
\text { (SRT) }\end{array}$ & $d$ & 14.64 & 13.78 & 20.49 & 15.62 \\
\hline
\end{tabular}


Results summarized in the Table 5 shows that the RBF operating with thick mat (higher carbon recovery) has the highest methane gas production (i.e., scenario - 3 has $1086 \mathrm{KgCH}_{4} / d$ ) and lowest aeration energy consumption (i.e., $3842 \mathrm{Kwh} / \mathrm{d}$ ) among all other scenarios. It may be because of the double layer formation when a thick mat is allowed on the belt surface which leads to overall higher TSS and COD removal from primary treatment. Some papers $[6,9]$ also indicate the same analogy as observed in scenario - 3 . Likewise, the SRT of the AS tank is also greatly influenced by the different types of primary treatment. The RBF with thick mat operating condition helps to enhance the SRT of the AS process (see Table 5) as it diverts most of the cellulose and other particulates to the AD. This is a clear advantage in terms of design aspect, i.e if an RBF with thick mat is selected as primary treatment instead of a PC then it may help to reduce the size of the AS tank for a given waste water load. Furthermore the enhanced SRT promotes the nitrification rate which helps to achieve the lowest effluent $\mathrm{NH}_{4}^{+}$concentration for scenario - 3 (see Table 5).

It is also observed that when an RBF operates without mat formation (scenario - 2), the denitrification rate improves significantly compared to the scenario - 3 as the RBF only removes cellulose and inert particulates. So the extra slowly biodegradable carbon directed to the treatment plant is utilized to achieve a lower TN effluent concentration. The observations from Rusten et al. [16] also indicates the same (i.e., improvement in denitrification) when an $\mathrm{RBF}$ is operated at a TSS removal efficiency equivalent to the scenario - 2. The effluent COD concentration for all the scenarios is below the discharge limit and no major difference is observed irrespective of primary technologies and operating conditions. Further, to explore the possible way to reduce the external carbon consumption (used for denitrification), the scenario - 4 is analyzed, where external carbon is not supplied to the anoxic tank and the plant is still able to meet the discharge limit (i.e., $<18 \mathrm{mg} / \mathrm{l}$ ). The key messages from the steady state analysis is that the RBF running with thick mat formation can lead 
to higher methane gas production from the $\mathrm{AD}$ and reduce aeration energy demand for the AS noticeably. The SRT of the AS tank and nitrification rate increases when higher carbon recovery by using $\mathrm{RBF}$ is preferred over PC. In other words it indicates a proper selection of primary technology can help to reduce the size of the AS tank and promote better nitrification. The external carbon demand (used for the denitrication process) can be reduced considerably without violating the average TN effluent discharge limit when the RBF runs without thick mat operating condition. This may be a suitable option for the plants scuffling with higher TN load.

\subsection{Implication of plant-wide dynamic analysis for a WWTP}

All the dynamic simulations (for each scenario) are carried out for 609 days in which the first 245 days are used for the plant to stabilize (i.e., to reach steady state) and then the last 364 days are used for plant performance evaluation. The proposed modified BSM2 framework (as depicted in Figure 2) along with the calibrated influent wastewater (dynamic profile is reported in the SI, Figure 1) are used for plant-wide dynamic simulation. The operating conditions (such as DO, TSS set point etc.) and particulates removal efficiency for the RBF (for the scenario - 2, 3,4) are assumed to be equal to the steady state condition (see the simulation strategy section for details).

From the dynamic simulation results (as summarized in the Table 6, Figure 5 and 6 ), it is clear that the average methane gas production from the $\mathrm{AD}$ increases when an $\mathrm{RBF}$ operates with thick mat (i.e., scenario - 3) which as a consequent has lowest aeration energy consumption (refer SI, Figure 6) compared to the other scenarios. It (scenario - 3) also boost the nitrification rate (see Table 6) compared to other scenarios. These patterns are in line with the understanding from the steady state analysis (see Table 5). 


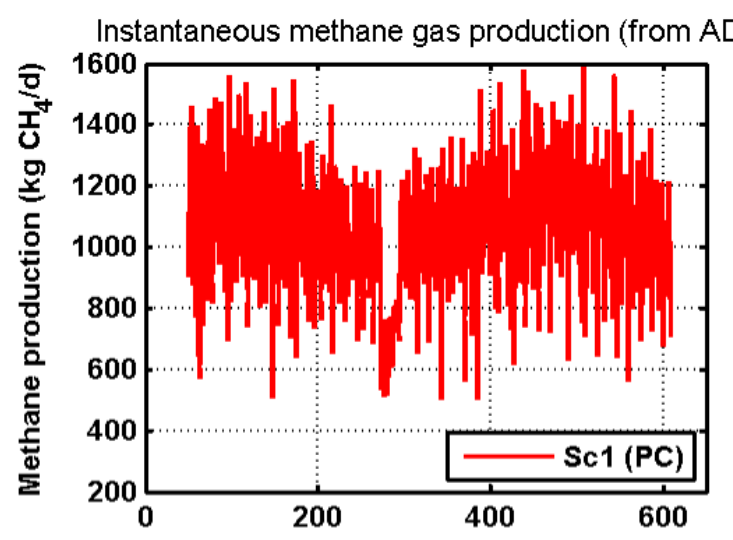

(a) Time (d)

Instantaneous methane gas production (from AD)

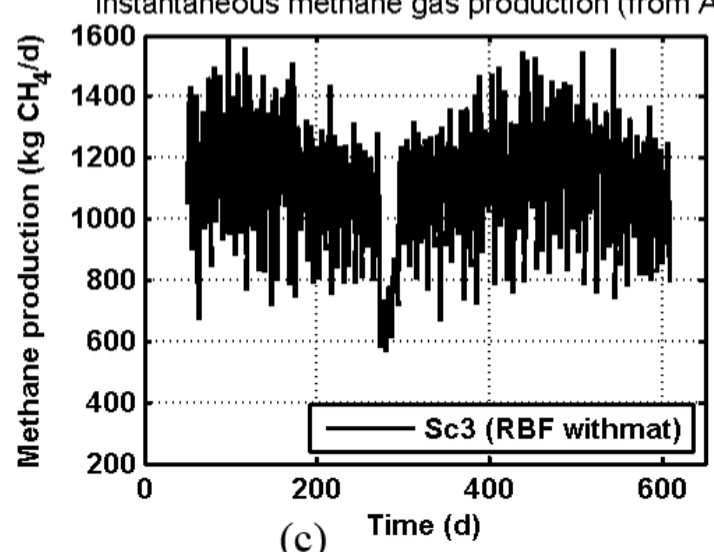

(c) Time (d)
Instantaneous methane gas production (from AD)

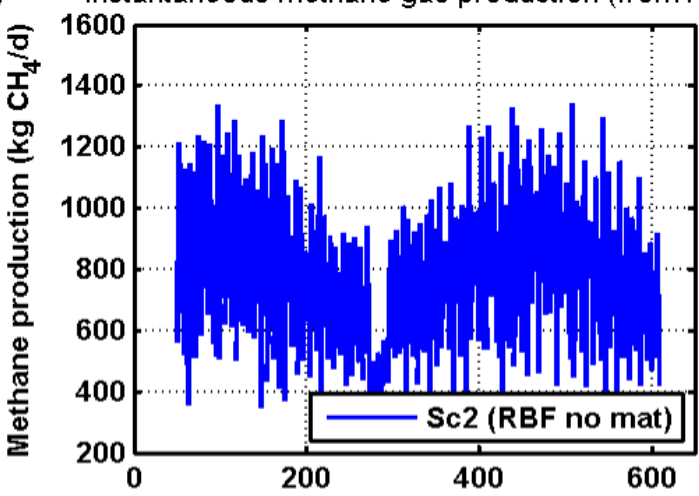

(b) Time (d)

Instantaneous methane gas production (from AD)

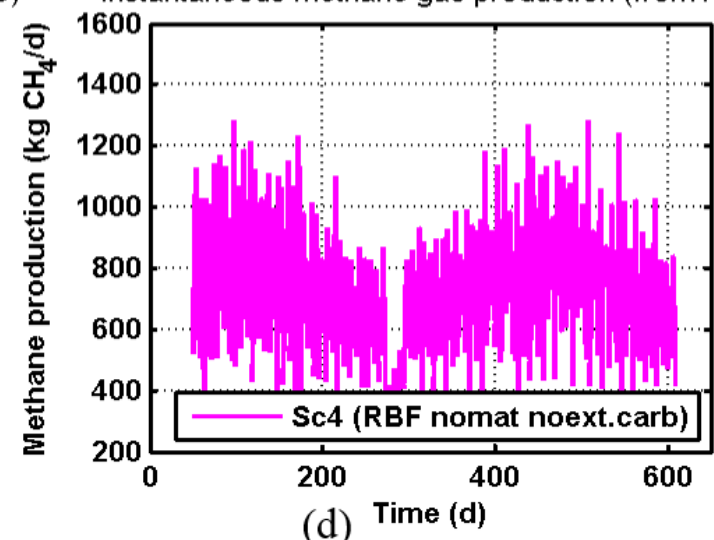

(d) Time (d)

Figure 5: Methane gas production from the AD (using closed loop dynamic simulation) : (a) scenario 1 (using PC), (b) scenario 2 (using RBF without thick mat) (c) scenario 3 (using RBF with thick mat) (d) scenario 4 (using RBF without thick mat and no addition of external carbon) 


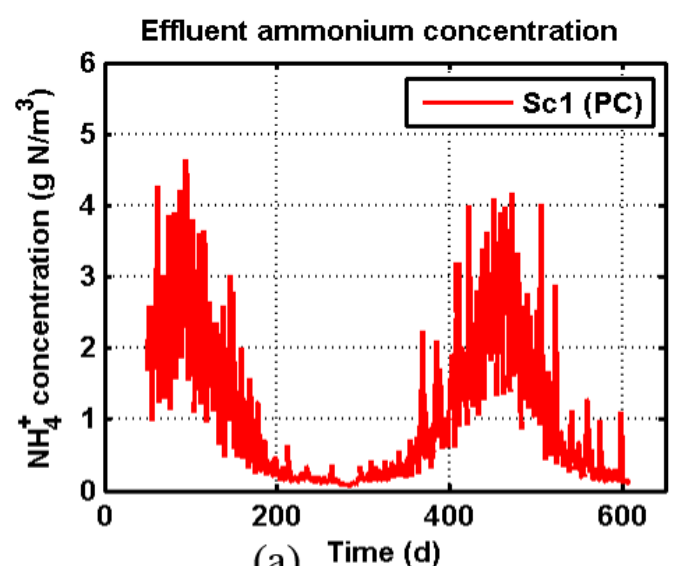

(a) Time (d)

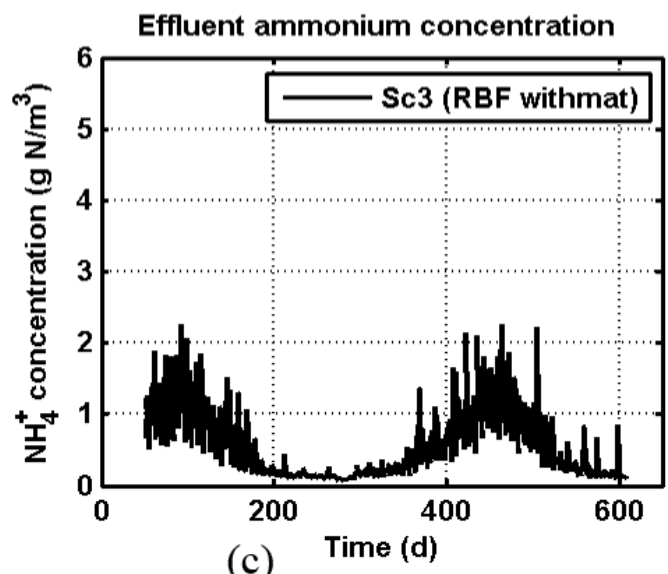

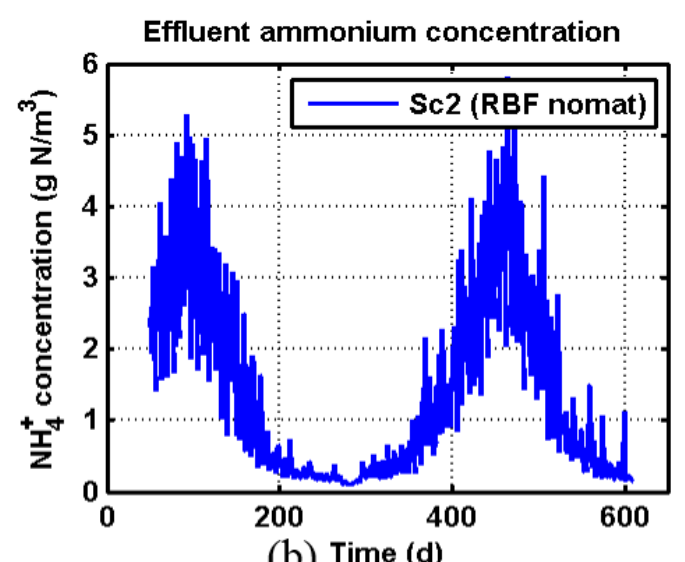

(b) Time (d)

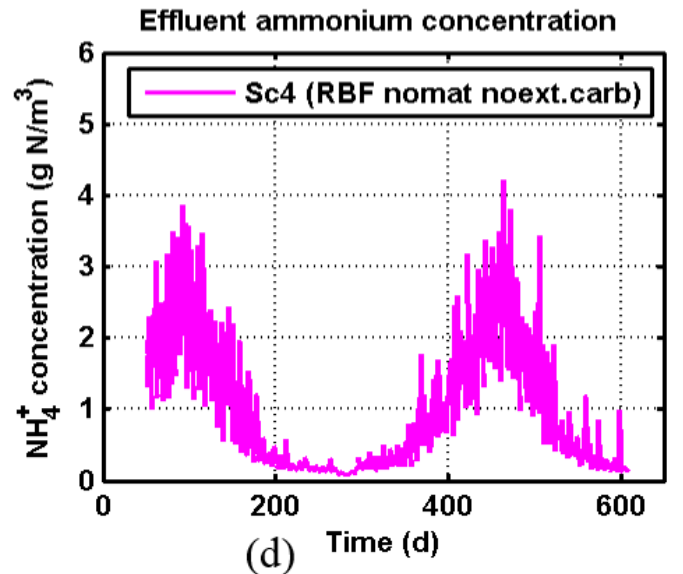

(d) Time (d)

Figure 6: Effluent ammonium concentration (using closed loop dynamic simulation) : (a) scenario 1 (using PC), (b) scenario 2 (using RBF without thick mat) (c) scenario 3 (using RBF with thick mat) (d) scenario 4 (using RBF without thick mat and no addition of external carbon) 
Table 6: Summary of key evaluation parameters results for all four scenarios, generated from the closed loop plant-wide dynamic simulation: scenario 1 (using PC), scenario 2 (using RBF without thick mat), scenario 3 (using RBF with thick mat), scenario 4 (using RBF without thick mat and no addition of external carbon).

\begin{tabular}{|c|c|c|c|c|c|}
\hline $\begin{array}{l}\text { Assessment param- } \\
\text { eters }\end{array}$ & Units & Sc -1 & Sc - 2 & Sc - 3 & Sc -4 \\
\hline $\begin{array}{l}\text { Average effluent COD } \\
\text { concentration }\end{array}$ & $g C O D \cdot m^{-} 3$ & 47.92 & 47.89 & 48.05 & 47.82 \\
\hline $\begin{array}{l}\text { Average effluent } \mathrm{TN} \\
\text { concentration }\end{array}$ & $g N . m^{-} 3$ & 12.17 & 11.37 & 15.69 & 13.75 \\
\hline $\begin{array}{l}\text { Average effluent am- } \\
\text { monium }\left(\mathrm{NH}_{4}^{+}\right) \text {con- } \\
\text { centration }\end{array}$ & $g N . m^{-} 3$ & 0.98 & 1.27 & 0.54 & 0.93 \\
\hline $\begin{array}{l}\text { Average effluent ni- } \\
\text { trate }\left(\mathrm{NO}_{3}^{-}\right) \text {concen- } \\
\text { tration }\end{array}$ & $g N . m^{-} 3$ & 9.22 & 8.01 & 13.10 & 10.76 \\
\hline $\begin{array}{l}\text { Average AE consump- } \\
\text { tion }\end{array}$ & $K w h . d^{-} 1$ & 4001 & 4354 & 3826 & 4221 \\
\hline $\begin{array}{l}\text { Average methane gas } \\
\text { production }\end{array}$ & $\mathrm{KgCH}_{4} \cdot \mathrm{d}^{-} 1$ & 1027 & 741 & 1087 & 691 \\
\hline Effluent quality index & Kgpoll.units.d $d^{-1}$ & 5459 & 5484 & 6040 & 5815 \\
\hline
\end{tabular}

The effluent discharge qualities (such as COD and TN) are met for all the scenarios (see Table 6), however it was observed that, at least for some of the time, the effluent TN concentration is violating the discharge limit (i.e., $>18 \mathrm{mg} / \mathrm{l}$ for $20 \%$ of operational time) for scenario - 3 (see SI, Table 7 and Figure 5), although the average effluent concentration is within the limit (see Table 6). In this context it is also important to note that the influent TN load (varies dynamically from $5 \mathrm{gN} / \mathrm{m}^{3}$ to $110 \mathrm{gN} / \mathrm{m}^{3}$ ) is relatively high for the considered plant. Similarly the EQI values for the scenario - 3 are relatively high (see Table 6) as it uses a high weighting factor for TKN and $\mathrm{NO}_{3}$ which indicates removal of nitrogen pollutants are also high priority. Likewise, the scenarios - 2 and 4 shows the methane gas production from the $\mathrm{AD}$ is lower compared to the other scenarios (i.e., 1 and 3) as the RBF is running at different operating conditions (i.e., without thick mat formation) which allows more organic carbon to the AS tank. Therefore, the aeration energy demand for both the scenarios is quite high and these findings are in line with steady-state analysis (see Table 5). 
Some positive aspects, such as meeting lowest effluent TN concentration (i.e., Scenario - 2) and saving external carbon dosage (i.e., scenario - 4) to the anoxic tank (for denitrification) are also observed (see Table 6).

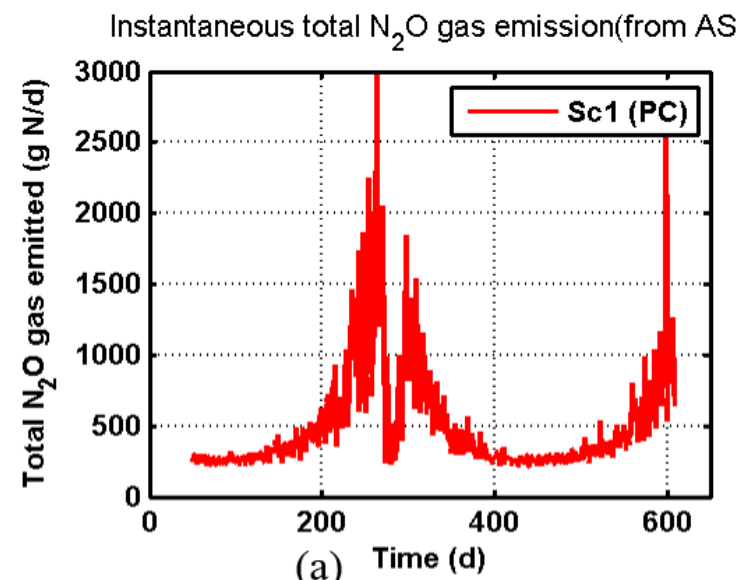

(a) Time (d)

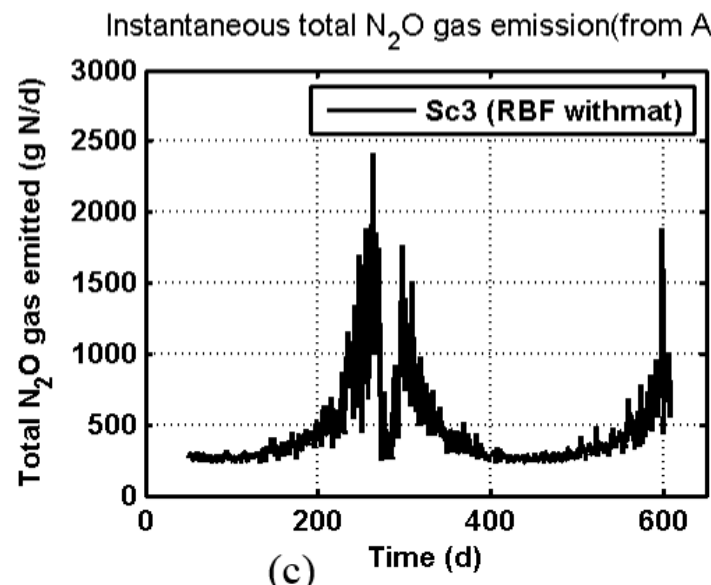

Instantaneous total $\mathrm{N}_{2} \mathrm{O}$ gas emission(from AS)

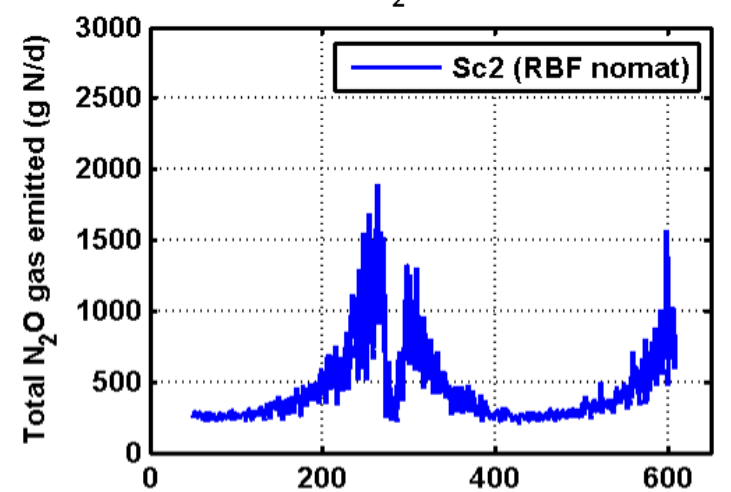

(b) Time (d)

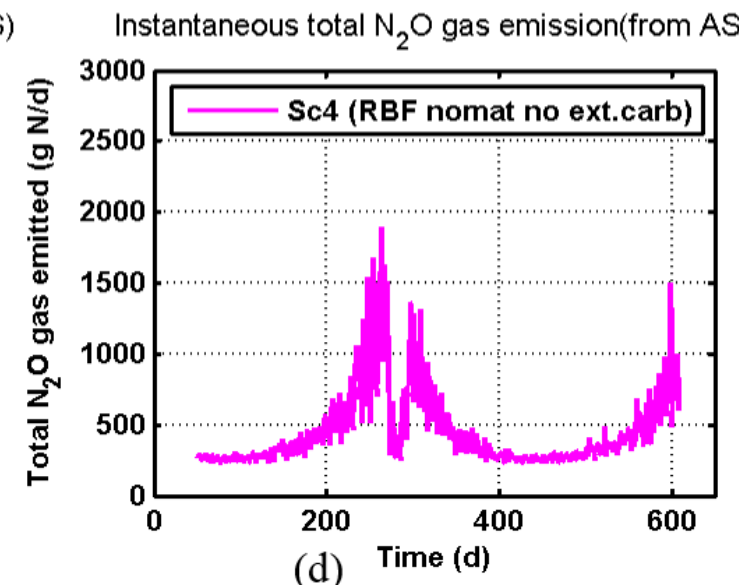

(d) Time (d)

Figure 7: Estimation of $\mathrm{N}_{2} \mathrm{O}$ gas emission from the activated sludge tank using two pathway model: (a) scenario 1 (using PC), (b) scenario 2 (using RBF without thick mat) (c) scenario 3 (using RBF with thick mat) (d) scenario 4 (using RBF without thick mat and no addition of external carbon)

During the plant-wide dynamic analysis, the impact of carbon recovery on $\mathrm{N}_{2} \mathrm{O}$ dynamics was also verified ( see Table 7) using two different pathway models. Both models indicate lower $\mathrm{N}_{2} \mathrm{O}$ emission factor $(<0.06 \%$ ) for all four scenarios which means the emission of $\mathrm{N}_{2} \mathrm{O}$ greenhouse gas is below the typical range ( varies from $0.1-2.8 \%$ [32]). As there are several factors [32] (such as DO, SRT, Temperature etc.) influencing the $\mathrm{N}_{2} \mathrm{O}$ emission, we 
Table 7: $\mathrm{N}_{2} \mathrm{O}$ gas emission comparison results (using closed loop plant-wide dynamic simulation) for all four scenarios using both one pathway and two pathway model: scenario 1 (using PC), scenario 2 (using RBF without thick mat), scenario 3 (using RBF with thick mat), scenario 4 (using RBF without thick mat and no addition of external carbon)

\begin{tabular}{|l|l|l|l|l|l|l|l|l|}
\hline \multirow{2}{*}{$\begin{array}{l}\text { Assessment param- } \\
\text { eters }\end{array}$} & \multicolumn{3}{|c|}{ One pathway model } & \multicolumn{5}{c|}{ Two pathway model } \\
\cline { 2 - 9 } & Sc-1 & Sc-2 & Sc-3 & Sc-4 & Sc-1 & Sc-2 & Sc-3 & Sc-4 \\
\hline $\begin{array}{l}N_{2} O \text { gas emission } \\
\left(g N . d^{-} 1\right)\end{array}$ & 651 & 543 & 562 & 550 & 546 & 479 & 502 & 485 \\
\hline $\begin{array}{l}N_{2} O \text { emission factor 1 } \\
\left(\% \frac{g N_{2} O-N_{\text {gas }}}{g T K N-N_{\text {in }}}\right)\end{array}$ & 0.057 & 0.046 & 0.046 & 0.046 & 0.054 & 0.045 & 0.047 & 0.046 \\
\hline $\begin{array}{l}N_{2} O \text { emission factor 2 } \\
\left(\% \frac{g N_{2} O-N_{\text {gas }}}{\left.g T K N-N_{\text {rem }}\right)}\right.\end{array}$ & 0.059 & 0.048 & 0.047 & 0.048 & 0.056 & 0.047 & 0.048 & 0.048 \\
\hline $\begin{array}{l}N_{2} O \text { produce by AOB } \\
\left(g N . d^{-} 1\right)\end{array}$ & 468 & 377 & 437 & 396 & 22137 & 21786 & 22448 & 22973 \\
\hline $\begin{array}{l}N_{2} O \text { produce by het- } \\
\text { erotrophs }\left(g N . d^{-} 1\right)\end{array}$ & 184 & 168 & 125 & 154 & -21589 & -21304 & -21945 & -22486 \\
\hline
\end{tabular}

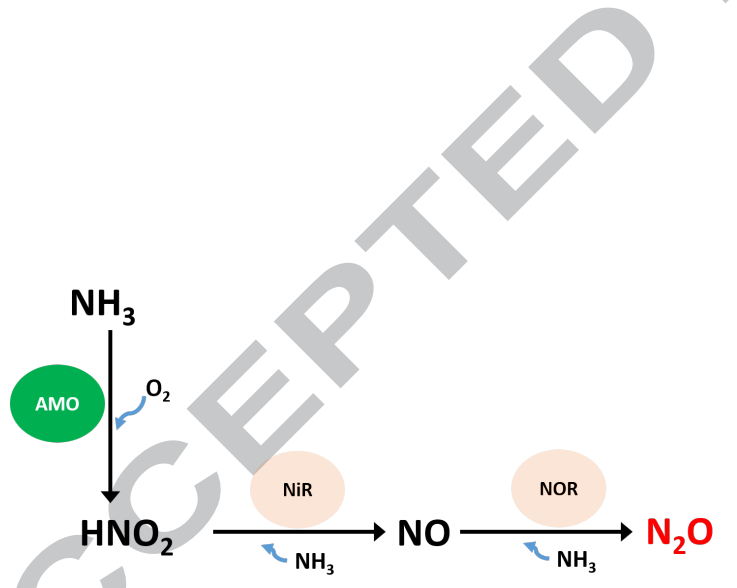

(a)
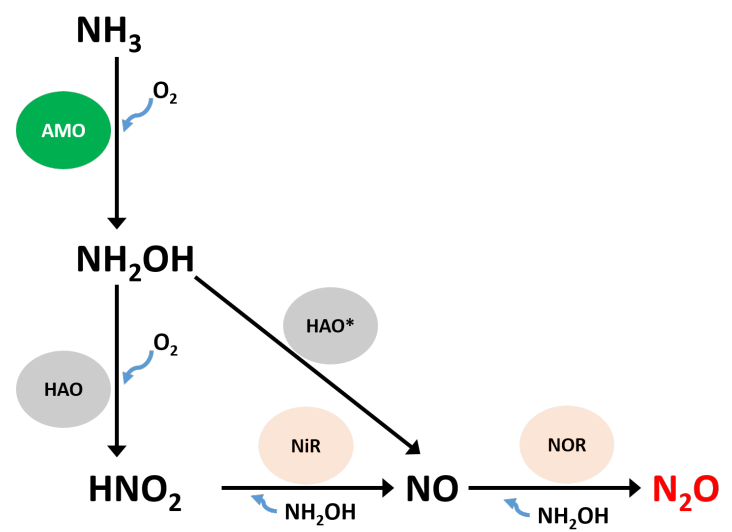

(b)

Figure 8: Two different model pathways for the $\mathrm{N}_{2} \mathrm{O}$ production by AOB (a) one-pathway[27] (b) twopathways[28]

anticipate (also reported in literature [34]) maintaining DO - $1 \mathrm{mg} / \mathrm{l}$ in all the three aerobic tanks and a moderate SRT $\left(\approx 15\right.$ days) are helping to limit the $N_{2} O$ gas emission below typical range. It is also observed that there are peaks in the $\mathrm{N}_{2} \mathrm{O}$ gas emission (see the Figure 7 for two pathway and SI, Figure 2 for one pathway ) when the $\mathrm{NO}_{2}^{-}$accumulation 
(see SI, Figure 4 and 3 for two pathway and one pathway, respectively) and the temperature during those periods are high (see SI, Figure 1 for temperature profile) which is an effect that is also reported in the literature [21, 34].

Thus, in summary the higher carbon recovery by the RBF (scenario - 3) helps to improve methane gas production, aeration energy consumption, nitrification rate and SRT of the AS at the cost of noticeable effluent TN offset. However, when the RBF is operated without thick mat formation (relatively low carbon recovery compared to other scenario) it is suitable for achieving better effluent TN removal. So there will be always a trade off which should be resolved based on the operating conditions as well as plant configuration and influent wastewater load. For example, if the objective is (or the plant need) to maximize the methane gas production by ensuring efficient mainline nitrogen removal technologies are in place (such as ANAMMOX based ) then the RBF with thick mat is the more suitable alternative. Likewise for a plant running at high TN load, RBF without thick mat is more preferable. It is also observered from the dynamic analysis that the organic carbon recovery using RBF does not increase the greenhouse gas $\left(\mathrm{N}_{2} \mathrm{O}\right)$ emission compared to the scenario employing PC. Both the $\mathrm{N}_{2} \mathrm{O}$ models (i.e one pathway and two pathways) indicate the $\mathrm{N}_{2} \mathrm{O}$ gas emission increases as the $\mathrm{NO}_{2}^{-}$accumulation and temperature increases which is in-line with the observations from Boiocchi et al. [35].

\subsection{Plant-wide sensitivity analysis for cellulose recovery}

As the cellulose content in the waste water can vary from site to site and the biodegradability of the cellulose in the AD and AS also depends on the operating parameters (such as Temperature, SRT etc.) and the type of cellulosic fibers, so it is essential to perform a plant-wide sensitivity analysis to further explore the limitation of cellulose recovery impact. Therefore, a local sensitivity analysis is carried out by varying the influent cellulose load from $25-40 \%$ [1]. Likewise the biodegradability of the cellulose in the AD is varied from 


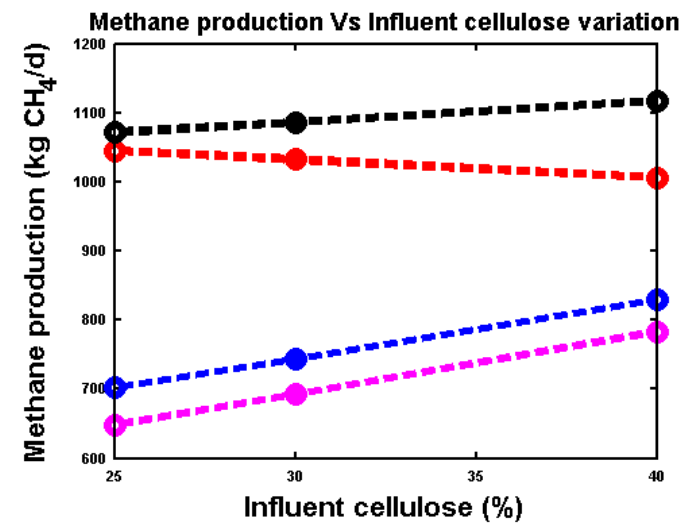

(a)

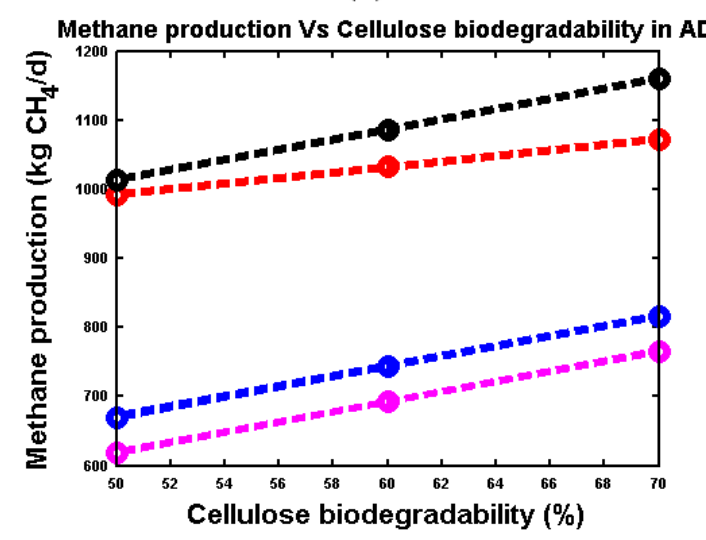

(c)

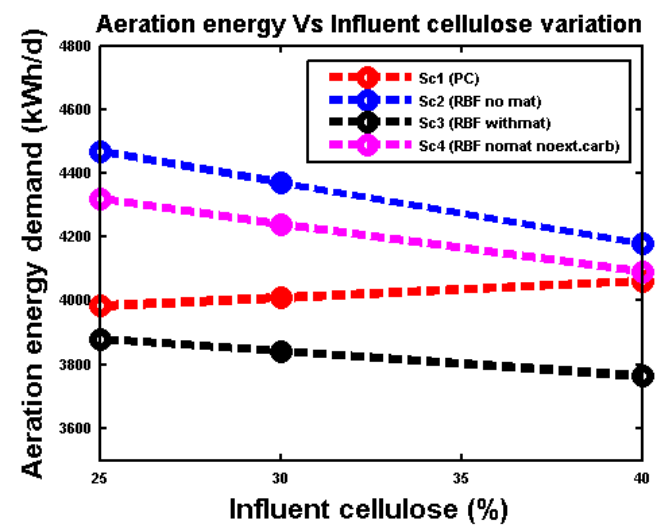

(b)

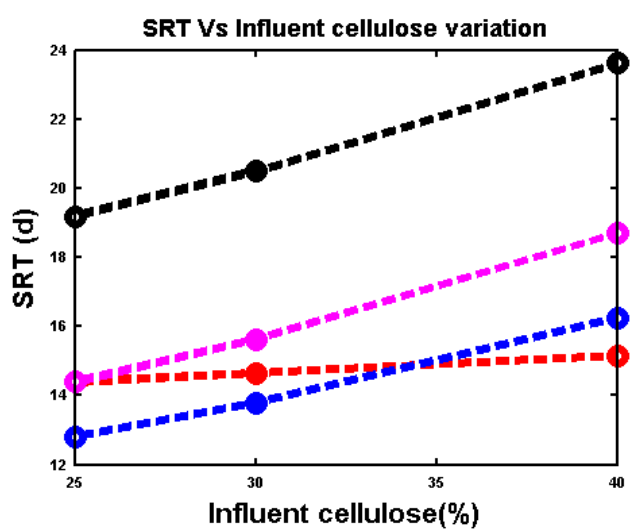

(d)

Figure 9: Sensitivity analysis using influent cellulose load and its biodegradability in the AD : (a) methane gas production w.r.t influent cellulose load (b) aeration energy demand w.r.t influent cellulose load (c) methane gas production w.r.t cellulose biodegradability in the AD (d) sludge retention time of AS tank w.r.t influent cellulose load

$50-70 \%[2,37]$ whereas in the AS it is assumed to be $15-35 \%[3]$.

The sensitivity analysis study (Figure 9 - a, b, d ) indicates that with an increase in influent cellulose load, the methane gas production in the AD increases for the RBF (i.e for scenario - 2, 3,4) and decreases for the PC (i.e scenario - 1). At the same time the AE demand for the AS process decreases for the RBF and increases for the PC. The scenario - 3 (suitable candidate as found in the plant-wide analysis) has approximately $10 \%$ higher methane gas production than scenario - 1 (with the PC). Similarly, the SRT of the AS 
tank dramatically increases (55\% higher for scenario-3 compared to scenario - 1) as the influent cellulose concentration increases. It is a quite important observation from a plant design prospective which means using the RBF, the size of an AS tank can be reduced. The aeration energy consumption for the scenario - 3 is about $8 \%$ lower compared to scenario 1 (with the PC, refer to SI, Table 8, 9, 10, 11). Likewise, for scenario - 2 and 4 , the methane gas production pattern increases and the aeration energy demand declines (in contrast to scenario - 1) as the influent cellulose concentration increases. This is because of the RBF's ability to recover cellulose fibers with higher efficiency compared to the PC. Similar trends (as for Scenario - 2 and 4) are also observed for the SRT of the AS tank. It is intuitive that the use of toilet paper ( the primary source of cellulose fibers in the WW) is expected to increase exponentially based on population and economic growth which will later promote the concept of carbon recovery through $\mathrm{RBF}$ like technologies. In addition to that, the biodegradability of cellulose has a positive impact (i.e., with an increase in biodegradability, methane gas production increases) for all the scenarios including the PC (see Figure 9 (c)). Thus, the surge in the methane gas production from the AD can be attributed to the higher organic carbon recovery and the biodegradability of cellulose fibers. The sensitivity analysis results also reveal the limitation of RBF influence on plant performance, i.e. with the lower influent cellulose concentration in the waste water the differences in methane gas production and AE demand between scenario - 3 and 1 are negligible. Thus consideration of RBF technology over the PC should be site specific which depends on plant design, wastewater load and composition.

\section{Conclusions}

Higher organic carbon recovery by an RBF leads to a significant surge in the methane gas production (in the $\mathrm{AD}$ ) and a notable reduction in the aeration energy demand (in the AS). Furthermore, the SRT of the AS tank increases which in turn contributes to achieve 
a better nitrification rate. Both the $\mathrm{N}_{2} \mathrm{O}$ models (i.e., one pathway and two pathways) indicate that the RBF does not promote greenhouse gas $\left(\mathrm{N}_{2} \mathrm{O}\right)$ emission which is primarily due to the increase in $\mathrm{NO}_{2}^{-}$accumulation. Sensitivity analysis reveals that the additional benefits of the RBF technology are difficult to realize at lower influent cellulose load to the plant. Therefore, the selection of higher carbon recovery technology should be based on plant configuration and influent wastewater load and composition.

Further investigations are required to understand the extent of biodegradability of cellulose fibers both in aerobic conditions (as proposed in Benneouala et al. [38]) and anaerobic condition (as proposed in Chen et al. [5]) and subsequently extend the rate expression for plant-wide analysis. Moreover the literature [37] suggests that the biodegradability of cellulose also depends on the type of cellulosic fibers (such as virgin fibers based toilet paper, recycled fiber based toilet paper, micro crystalline cellulose etc.). It is also required to investigate further the biodegradability of cellulose by mixing with other co-substrate (such as sludge produced from the secondary clarifier) which may enhance the cellulose biodegradability [5]. Furthermore, an extension of the organic carbon recovery model to different operating conditions (such as chemical addition, without thick mat formation, explicitly varying the sieving rate, water level, etc.) will help to explore different operating strategies in terms of RBF performance, and its impact on plant-wide performance. For example, an impact assessment of the combination of RBF (as primary treatment) and an ANAMMOX based mainline nitrogen removal process (such as IFAS) impact assessment will be an useful study. A full-scale plant validation with an RBF will refine the understanding of the potential of carbon recovery concept.

\section{Nomenclature}


Table 8: List of acronyms used in the present study

\begin{tabular}{|c|c|}
\hline Acronyms & Descriptions \\
\hline RBF & Rotating Belt Filter \\
\hline PC & Primary Clarifier \\
\hline AS & Activated Sludge \\
\hline AD & Anaerobic Digestion \\
\hline ASM1 & Activated Sludge Model No.1 \\
\hline ADM1 & Anaerobic Digestion Model No. 1 \\
\hline WW & Waste Water \\
\hline COD & Ehemical Oxygen Demand \\
\hline EQI & Total Nitrogen \\
\hline TN & Wastewater Treatment Plant \\
\hline WWTP & Total Suspended Solids \\
\hline TSS & Dissolved Oxygen \\
\hline BSM2 & Proportional Integral \\
\hline DO & Biological Oxygen Demand \\
\hline PI & Total Suspended Solids \\
\hline BOD & Total kjeldahl Nitrogen \\
\hline TSS & Total Nitrogen \\
\hline TKN & Aeration Energy \\
\hline TN & Ammonium Oxidizing Bacteria \\
\hline AE & Heterotrophic Bacteria \\
\hline AOB & Antegrated Fixed-Film Activated Sludge \\
\hline HB & ANaerobic AMMonium OXidation \\
\hline IFAS & \\
\hline ANAMMOX & Andimulation Model No. \\
\hline & Andex \\
\hline
\end{tabular}




\section{Acknowledgement}

This work is part of PIONEER STP project which is funded by Water Joint Programming Initiative, water challenge for a changing world waterworks 2014 co fund call. Dr. Ulf Jeppsson (Lund University) and Dr. Riccardo Boiocchi are gratefully acknowledged for providing the codes of the Benchmark Simulation Models.

\section{Supplementary information}

Supplementary data associated with this article can be found in a separate file named Appendix A1.

\section{References}

[1] C. Ruiken, G. Breuer, E. Klaversma, T. Santiago, M. Van Loosdrecht, Sieving wastewater-Cellulose recovery, economic and energy evaluation, Water research 47 (1) (2013) 43-48.

[2] D. S. Ghasimi, Y. Tao, M. de Kreuk, B. Abbas, M. H. Zandvoort, J. B. van Lier, Digester performance and microbial community changes in thermophilic and mesophilic sequencing batch reactors fed with the fine sieved fraction of municipal sewage, Water research 87 (2015) 483-493.

[3] H. Verachtert, K. Ramasamy, M. Meyers, J. Bevers, Investigations on cellulose biodegradation in activated sludge plants, Journal of Applied Microbiology 52 (2) (1982) 185-190.

[4] B. Metcalf \& Eddy, G. Tchobanoglous, Wastewater Engineering: Treatment Disposal Reuse, Central Book Company, 1980.

[5] R. Chen, Y. Nie, H. Kato, J. Wu, T. Utashiro, J. Lu, S. Yue, H. Jiang, L. Zhang, Y.-Y. Li, Methanogenic degradation of toilet-paper cellulose upon sewage treatment in an anaerobic membrane bioreactor at room temperature, Bioresource technology 228 (2017) 69-76.

[6] B. Paulsrud, B. Rusten, B. Aas, Increasing the sludge energy potential of wastewater treatment plants by introducing fine mesh sieves for primary treatment, Water Science and Technology 69 (3) (2014) $560-565$.

[7] A. Franchi, D. Santoro, Current status of the rotating belt filtration (RBF) technology for municipal wastewater treatment, Water Practice and Technology 10 (2) (2015) 319-327. 
[8] Z. S. Dang Ho, S. Sarathy, D. Santoro, Enhanced primary treatment, Innovative Wastewater Treatment \& Resource Recovery Technologies: Impacts on Energy, Economy and Environment (2017) 155.

[9] B. Rusten, H. Ødegaard, Evaluation and testing of fine mesh sieve technologies for primary treatment of municipal wastewater, Water science and technology 54 (10) (2006) 31-38.

[10] Z. Jin, H. Gong, H. Temmink, H. Nie, J. Wu, J. Zuo, K. Wang, Efficient sewage pre-concentration with combined coagulation microfiltration for organic matter recovery, Chemical Engineering Journal 292 (2016) 130-138.

[11] H. Gong, Z. Wang, X. Zhang, Z. Jin, C. Wang, L. Zhang, K. Wang, Organics and nitrogen recovery from sewage via membrane-based pre-concentration combined with ion exchange process, Chemical Engineering Journal 311 (2017) 13-19.

[12] C. T. DeGroot, E. Sheikholeslamzadeh, A. Soleymani, D. Santoro, D. J. Batstone, D. Rosso, Understanding primary treatment performance and carbon diversion potential of rotating belt filters using computational fluid dynamics, Proceedings of the Water Environment Federation 2015 (6) (2015) 12491262.

[13] C. T. DeGroot, E. Sheikholeslamzadeh, D. Santoro, S. Sarathy, T.-O. Lyng, Y. Wen, F. DaynouriPancio, D. Rosso, Dynamic Modeling of Rotating Belt Filters Enables Design Exploration and Advanced Sizing With Varying Influent Conditions, Proceedings of the Water Environment Federation 2016 (14) (2016) 1158-1168.

[14] A. Franchi, K. Stedman, C. Mitchell, Demonstration-Scale of Primary Solids Harvesting for Energy Recovery at the UC Davis Wastewater Treatment Plant, Proceedings of the Water Environment Federation 2012 (10) (2012) 5699-5714.

[15] R. Jansen, Successful pilot test of rotating belt filters, Filtration+ Separation 53 (4) (2016) 26-27.

[16] B. Rusten, V. Razafimanantsoa, M. Andriamiarinjaka, C. Otis, A. Sahu, T. Bilstad, Impact of fine mesh sieve primary treatment on nitrogen removal in moving bed biofilm reactors, Water Science and Technology 73 (2) (2016) 337-344.

[17] V. Razafimanantsoa, L. Ydstebø, T. Bilstad, A. Sahu, B. Rusten, Effect of selective organic fractions on denitrification rates using Salsnes Filter as primary treatment, Water Science and Technology 69 (9) (2014) 1942-1948.

[18] K. V. Gernaey, U. Jeppsson, P. A. Vanrolleghem, J. B. Copp, Benchmarking of control strategies for wastewater treatment plants, IWA Publishing, 2014.

[19] U. Jeppsson, C. Rosen, J. Alex, J. Copp, K. V. Gernaey, M.-N. Pons, P. A. Vanrolleghem, Towards a 
benchmark simulation model for plant-wide control strategy performance evaluation of WWTPs, Water Science and Technology 53 (1) (2006) 287-295.

[20] R. Boiocchi, Plant-wide modelling and control of nitrous oxide emissions from wastewater treatment plants, Ph.D. thesis, Technical University of Denmark, 2016.

[21] R. Boiocchi, K. V. Gernaey, G. Sin, Understanding N 2 O formation mechanisms through sensitivity analyses using a plant-wide benchmark simulation model, Chemical Engineering Journal 317 (2017) $935-951$.

[22] K. Solon, X. Flores-Alsina, C. K. Mbamba, D. Ikumi, E. Volcke, C. Vaneeckhaute, G. Ekama, P. Vanrolleghem, D. J. Batstone, K. Gernaey, U.Jeppsson, Plant-wide modelling of phosphorus transformations in wastewater treatment systems: Impacts of control and operational strategies, Water Research 113 (2017) 97-110.

[23] M. Henze, W. Gujer, T. Mino, M. Van Loosdrecht, Activated sludge models ASM1, ASM2, ASM2d and ASM3, IWA publishing, 2000.

[24] I. Takács, G. G. Patry, D. Nolasco, A dynamic model of the clarification-thickening process, Water research 25 (10) (1991) 1263-1271.

[25] D. J. Batstone, J. Keller, I. Angelidaki, S. Kalyuzhnyi, S. Pavlostathis, A. Rozzi, W. Sanders, H. Siegrist, V. Vavilin, The IWA anaerobic digestion model no 1 (ADM1), Water Science and Technology 45 (10) (2002) 65-73.

[26] W. C. Hiatt, C. Grady, An updated process model for carbon oxidation, nitrification, and denitrification, Water Environment Research 80 (11) (2008) 2145-2156.

[27] L. Guo, P. A. Vanrolleghem, Calibration and validation of an activated sludge model for greenhouse gases no. 1 (ASMG1): prediction of temperature-dependent N2O emission dynamics, Bioprocess and biosystems engineering 37 (2) (2014) 151-163.

[28] C. Domingo-Félez, B. F. Smets, A consilience model to describe N 2 O production during biological N removal, Environmental Science: Water Research \& Technology 2 (6) (2016) 923-930.

[29] G. Sin, K. V. Gernaey, M. B. Neumann, M. C. van Loosdrecht, W. Gujer, Uncertainty analysis in WWTP model applications: a critical discussion using an example from design, Water Research 43 (11) (2009) 2894-2906.

[30] K. V. Gernaey, X. Flores-Alsina, C. Rosen, L. Benedetti, U. Jeppsson, Dynamic influent pollutant disturbance scenario generation using a phenomenological modelling approach, Environmental Modelling \& Software 26 (11) (2011) 1255-1267. 
[31] R. Otterpohl, M. Freund, Dynamic models for clarifiers of activated sludge plants with dry and wet weather flows, Water science and Technology 26 (5-6) (1992) 1391-1400.

[32] M. J. Kampschreur, H. Temmink, R. Kleerebezem, M. S. Jetten, M. C. van Loosdrecht, Nitrous oxide emission during wastewater treatment, Water research 43 (17) (2009) 4093-4103.

[33] Y. Wang, X. Lin, D. Zhou, L. Ye, H. Han, C. Song, Nitric oxide and nitrous oxide emissions from a full-scale activated sludge anaerobic/anoxic/oxic process, Chemical Engineering Journal 289 (2016) $330-340$.

[34] X. Flores-Alsina, L. Corominas, L. Snip, P. A. Vanrolleghem, Including greenhouse gas emissions during benchmarking of wastewater treatment plant control strategies, water research 45 (16) (2011) 47004710 .

[35] R. Boiocchi, K. V. Gernaey, G. Sin, A novel fuzzy-logic control strategy minimizing N2O emissions, Water Research 123 (2017) 479-494.

[36] G. A. Seber, C. Wild, Nonlinear regression. Wiley series in probability and mathematical statistics, 1989.

[37] D. S. Ghasimi, M. H. Zandvoort, M. Adriaanse, J. B. van Lier, M. de Kreuk, Comparative analysis of the digestibility of sewage fine sieved fraction and hygiene paper produced from virgin fibers and recycled fibers, Waste Management 53 (2016) 156-164.

[38] M. Benneouala, Y. Bareha, E. Mengelle, M. Bounouba, M. Sperandio, Y. Bessiere, E. Paul, Hydrolysis of particulate settleable solids (PSS) in activated sludge is determined by the bacteria initially adsorbed in the sewage, Water Research . 